\title{
Volume 1 : Table des matières
}

Liste des contributeurs de la Grande Grammaire Historique du Français . . . . . . . . V VII

Liste des conventions d'écriture et abréviations utilisées dans la Grande

Grammaire Historique du Français

\section{Introduction}

Principes de la Grande Grammaire Historique du Français (GGHF) . . . . 1

\section{Chapitre 1}

Une Grammaire historique de l'an 2020 (CMN, BC, TS et SP) $\ldots \ldots \ldots$

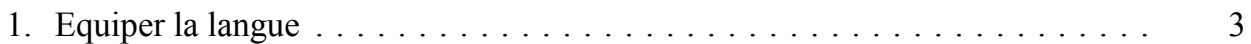

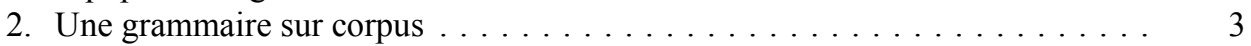

3. Nouveaux domaines de la grammaire historique : graphématique, sémantique grammaticale, énonciation et pragmatique $\ldots \ldots \ldots \ldots \ldots \ldots \ldots$

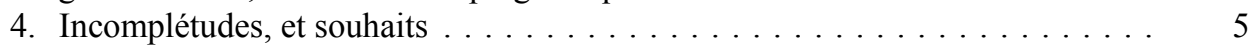

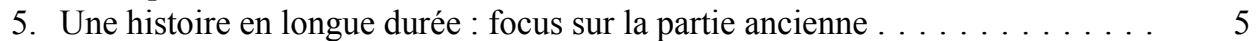

6. Une grammaire du changement . . . . . . . . . . . . . . . . . 6

7. «Tout changement est une variante qui a réussi » : penser la variation ..... 7

8. La langue comme système dynamique, le signe linguistique comme muable . . 8

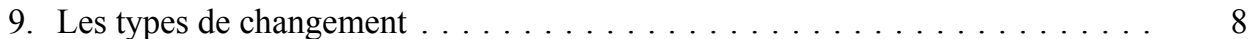

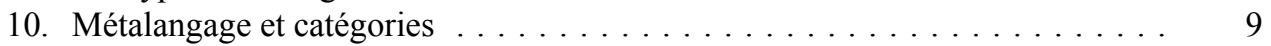

11. Une longue et dense tradition $\ldots \ldots \ldots \ldots \ldots \ldots \ldots \ldots \ldots \ldots$

\section{Partie 1}

Fondements théoriques et méthodologie (SP).

\section{Chapitre 2}

L'approche du changement linguistique dans la Grande Grammaire

Historique du Français (SP et MD) .

2.1 La notion de « théorie » du changement linguistique est-elle pertinente ? . . . 15

2.2 Approche générativiste et approches fonctionnalistes du changement . . . . . . . 17

2.2.1 La grammaire générative et le changement linguistique . . . . . . . . . 17

2.2.2 Une approche « diachronique » et « fonctionnaliste » du

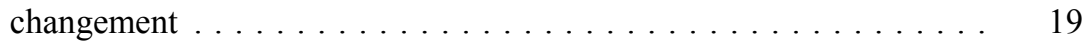

2.3 Qu'entend-on par changement linguistique $? \ldots \ldots \ldots \ldots \ldots \ldots \ldots \ldots$

2.4 La variation au cœur du changement linguistique. Rythme, vitesse et durée

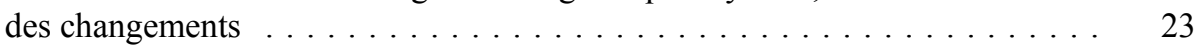

2.5 Mécanismes et processus à l'œuvre ; causes et motivations . . . . . . . . . . 27

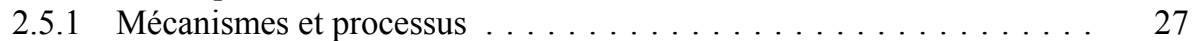

2.5.1.1 Réanalyse et analogie . . . . . . . . . . . . . . . 27

2.5 .1 .2 Processus . . . . . . . . . . . . . . . . . . 28 
2.5.2 La question de la directionnalité du changement $\ldots \ldots \ldots \ldots \ldots$

2.5.3 Les causes du changement . . . . . . . . . . . . . 32

2.6 Difficultés méthodologiques d'une approche diachronique pour les états

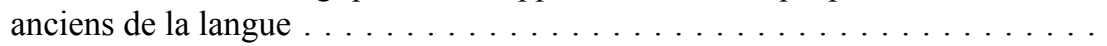

\section{Chapitre 3}

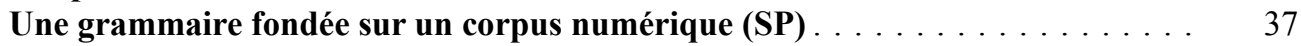

3.1 Une histoire de la langue française $\ldots \ldots \ldots \ldots \ldots \ldots \ldots \ldots \ldots \ldots \ldots$

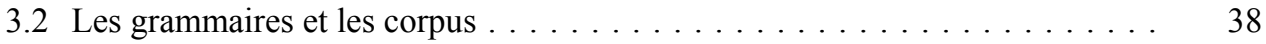

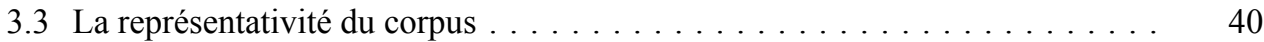

3.4 Nos choix, notre démarche $\ldots \ldots \ldots \ldots \ldots \ldots \ldots \ldots \ldots \ldots . \ldots \ldots . \ldots \ldots$

3.4.1 Un corpus à géométrie variable $\ldots \ldots \ldots \ldots \ldots \ldots \ldots \ldots \ldots \ldots \ldots$

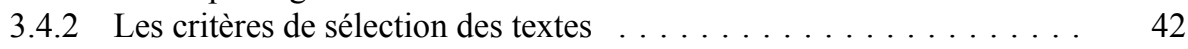

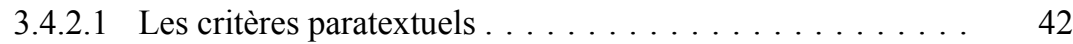

3.4.2.2 Les descripteurs . . . . . . . . . . . . . . . 43

a. La date des textes ............... 43

b. La forme des textes : vers / prose ......... 43

c. Les dialectes $\ldots \ldots \ldots \ldots \ldots \ldots \ldots \ldots \ldots$. 44

d. Les domaines et les genres . . . . . . . . . . . 44

3.4.3 La représentation de l'oral . . . . . . . . . . . . . . 44

3.5 Liste des textes du corpus de la GGHF $\ldots \ldots \ldots \ldots \ldots \ldots \ldots \ldots$

\section{Chapitre 4}

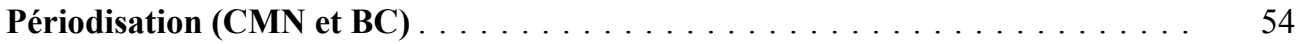

4.1 Quelle périodisation pour une grammaire historique du français ? . . . . . 54

4.2 Les pratiques des historiens de la langue . . . . . . . . . . . 55

4.3 Une périodisation sur des bases purement linguistiques est-elle possible ? . . . 56

4.4 Un cas d'école : l'invention du « français préclassique » . . . . . . . . 57

4.5 La progressivité des changements . . . . . . . . . . . . . . . . . . 59

\section{Partie 2}

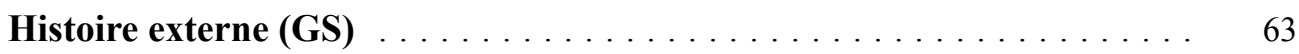

\section{Chapitre 5}

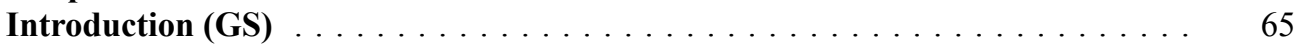

5.1 Qu'entend-on par « histoire externe » $\ldots \ldots \ldots \ldots \ldots \ldots \ldots \ldots .65$

5.2 Quelles sont les données non linguistiques importantes à prendre en compte ? 67

5.3 Comment articuler histoire interne et histoire externe ? La place du sujet

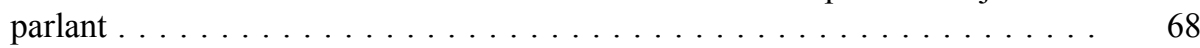

5.4 Y a-t-il des périodisations différentes en « histoire interne » et en « histoire externe»? 


\section{Chapitre 6}

Que peut-on appeler « français », et à quelle époque $\quad$ (GS) $\ldots \ldots \ldots$. . . . . . 73

6.1 La modification des systèmes d'opposition . . . . . . . . . . . . . . 73

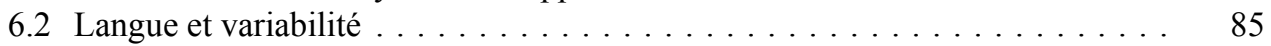

\section{Chapitre 7}

Les données historiques, géographiques et démographiques (GS) . . . . . . . . 91

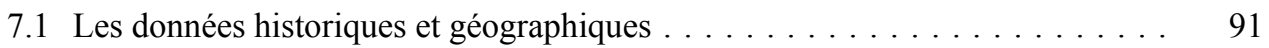

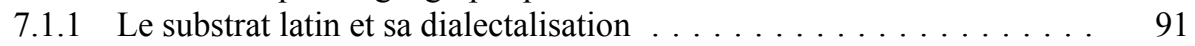

7.1.2 Influences précoces . . . . . . . . . . . . . . . . . . 92

7.1 .3 La dialectalisation $d u \operatorname{roman} \ldots \ldots \ldots \ldots \ldots \ldots$

7.1.4 La diffusion du français sur le territoire . . . . . . . . . . . . . . . . . . . . 99

7.1.5 Le français langue de culture en Europe . . . . . . . . . . . . . . . . . 102

7.1.6 La colonisation et la décolonisation . . . . . . . . . . . . . . . . . 103

7.2 Les données démographiques . . . . . . . . . . . . . . . . . . . . . . . . . . . . . . . . . . . . . . 104

7.2 .1 Le nombre de locuteurs . . . . . . . . . . . . . . . . . . . 104

7.2.2 Structure et mobilité de la population . . . . . . . . . . . . 107

\section{Chapitre 8}

Colinguismes et contacts de langues (GS) $\ldots \ldots \ldots \ldots \ldots \ldots$

8.1 Les colinguismes . . . . . . . . . . . . . . . . . . . 110

8.1.1 Le colinguisme latin / dialecte / français . . . . . . . . . . . . . 110

8.1 .2 Le devenir du latin . . . . . . . . . . . . . . . . . . . . . . . . 112

8.1 .3 Le devenir des vernaculaires . . . . . . . . . . . . . . . . . . . . . 115

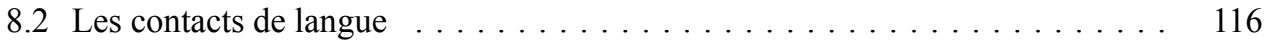

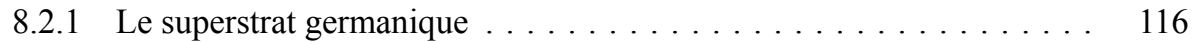

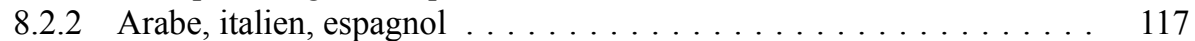

8.2 .3 L'anglais . . . . . . . . . . . . . . . . . . . . . . . . . . 118

8.2.4 Le français et les langues du monde . . . . . . . . . . . . . . . . . . 119

\section{Chapitre 9}

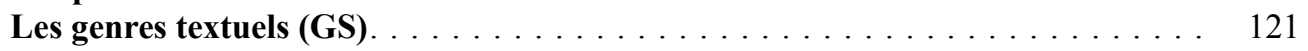

9.1 «Genres », «types » et traditions discursives . . . . . . . . . . . . . 121

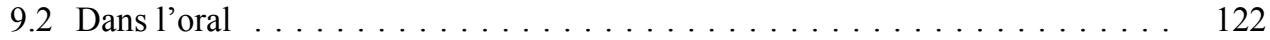

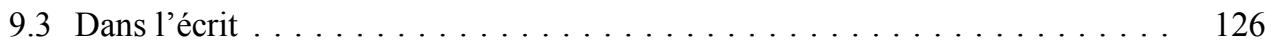

9.3.1 Naissance des genres littéraires . . . . . . . . . . . . . . . . . . . . . . . . . . . . 127

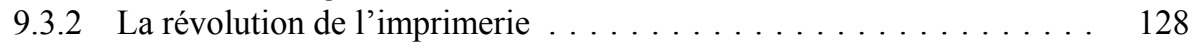

9.3.3 De nouveaux genres textuels . . . . . . . . . . . . . . 131 


\section{Chapitre 10}

Les interventions sur les parlers, l'équipement de la langue, les facteurs

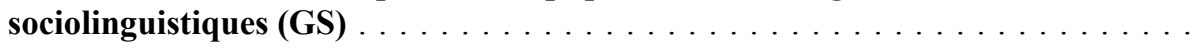

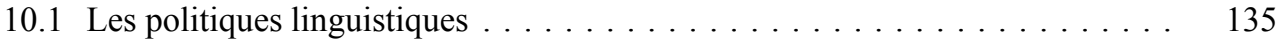

10.1 .1 En France . . . . . . . . . . . . . . . . . . . . . . . . . . 135

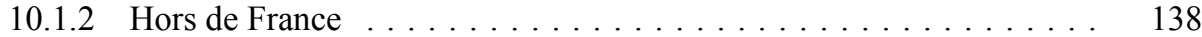

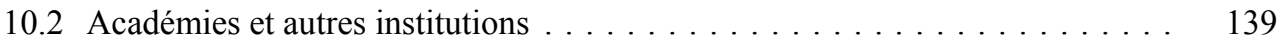

10.3 Discours métalinguistiques, équipements de la langue et normes . . . . . . . . 141

10.3.1 Le développement du métalinguistique . . . . . . . . . . . . 141

10.3.2 Les équipements techniques de la langue . . . . . . . . . . . . . . 142

10.3.3 Les normes implicites . . . . . . . . . . . . . . . . . . . . 145

10.4 La culture de la langue . . . . . . . . . . . . . . . . . . . . 146

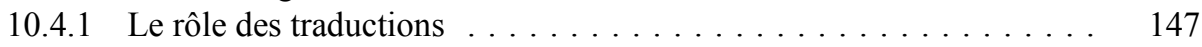

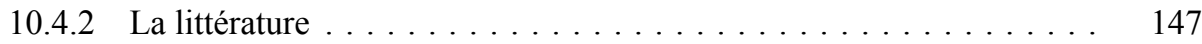

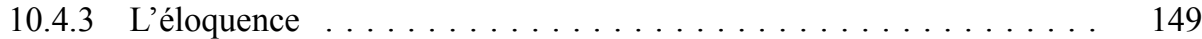

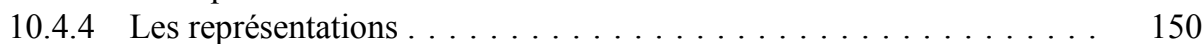

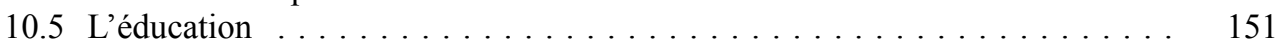

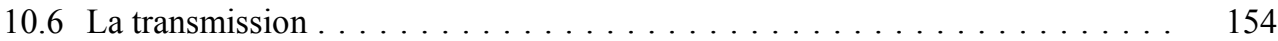

10.6.1 La transmission générationnelle . . . . . . . . . . . . . . 154

10.6.2 Effets de mode et parlers communautaires . . . . . . . . . . . . 154

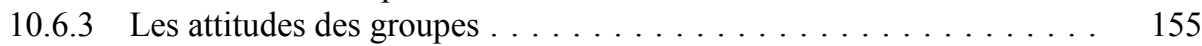

\section{Partie 3}

Phonétique Historique (TS) $\ldots \ldots \ldots \ldots \ldots \ldots \ldots$

\section{Chapitre 11}

Introduction (aux chapitres 11-23) (TS et PS) . . . . . . . . . . . . . . . . . . . . 159

11.1 Phonétique historique du français . . . . . . . . . . . . . . . . . 159

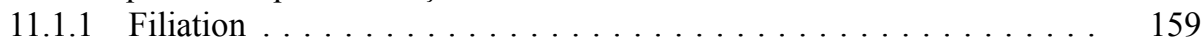

11.1.2 Organisation positionnelle et théorie phonologique moderne . . . . 159

11.1.3 La phonétique historique est d'abord celle qui va jusqu'à l'ancien français ......................... 160

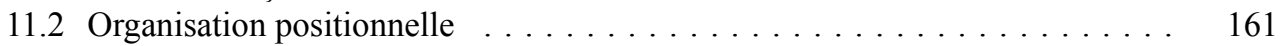

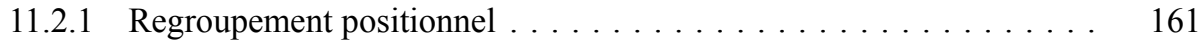

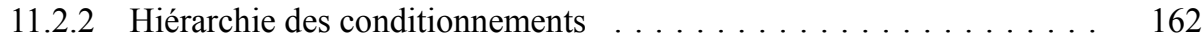

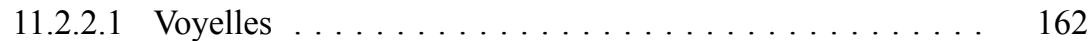

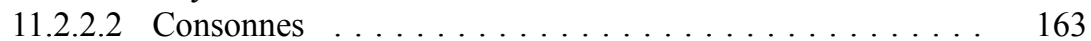

11.2.2.3 Interdiction des syllabes super-lourdes : ${ }^{*} \mathrm{C} \overline{\mathrm{V}} \mathrm{C}$,

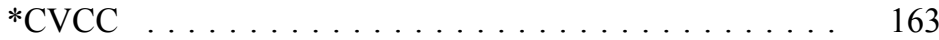

11.2.2.4 Position $>$ accent $>$ mélodie . . . . . . . . . . . 163

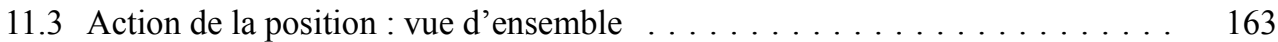

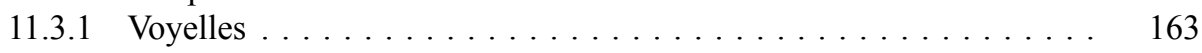

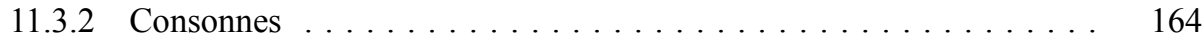

11.3.2.1 Hiérarchie : position forte $>$ intervocalique $>$ coda . . . . 164 
11.3.2.2 Illustration . . . . . . . . . . . . . . . 165

a. Evolution hors influence mélodique ......... 165

b. Position forte ................. 165

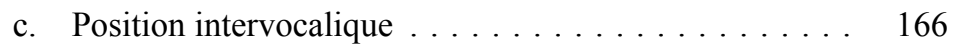

d. Coda ...................... 167

\section{Chapitre 12}

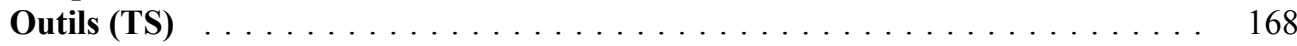

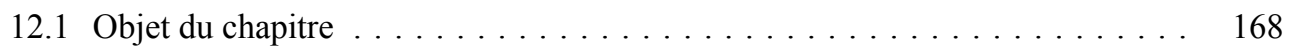

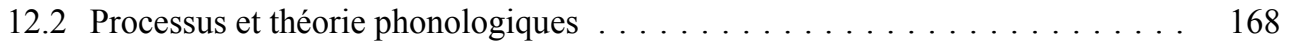

12.2.1 Action de la phonologie : trois types de processus . . . . . . . . . . . . 168

12.2.2 Usage de la théorie phonologique . . . . . . . . . . . . . . . . . . . 169

12.3 Structure interne des consonnes et voyelles . . . . . . . . . . . . . . . . . . . . . . . . . 169

12.4 Identité phonologique des positions syllabiques . . . . . . . . . . . . . . 170

12.4.1 Positions dans la chaîne linéaire et leur regroupement . . . . . . . . . 170

12.4.2 Identité phonologique des cinq positions syllabiques majeures . . . . 171

12.4.2.1 Structure autosegmentale, consonnes flottantes . . . . . . . . 171

12.4.2.2 Relations latérales : gouvernement et licenciement . . . . . 172

12.4.2.3 Unité de la position forte (Coda Miroir) . . . . . . . . . . . . 173

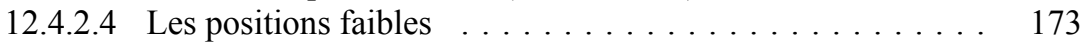

12.4.2.5 Syllabe ouverte vs. syllabe fermée . . . . . . . . . . . . . 174

12.4.2.6 Récapitulatif des identités phonologiques . . . . . . . . . . . 175

12.4.3 Attaque branchante (muta cum liquida) . . . . . . . . . . . . . . . . . . 175

12.4.3.1 Groupe consonantique tautosyllabique . . . . . . . . 175

12.4.3.2 Muta cum liquida moins tl, dl, vl . . . . . . . . . . . 176

12.4.4 Groupe triconsonantique $\mathrm{C}_{1} \mathrm{C}_{2} \mathrm{C}_{3}$ : élimination du $\mathrm{CV}$ médian . . . . . 176

12.4.4.1 Syncope et attaque branchante . . . . . . . . . . 176

12.4.4.2 Elimination du CV médian : inventaire . . . . . . . . . . . . . . . . . . . . . . . . . . . . . . . .

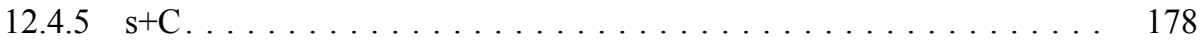

12.4.6 Accent et allongement tonique . . . . . . . . . . . . . . . . . 179

12.4.6.1 Proéminence. . . . . . . . . . . . . . . . . . 179

12.4.6.2 Allongement tonique . . . . . . . . . . . . . . . 180

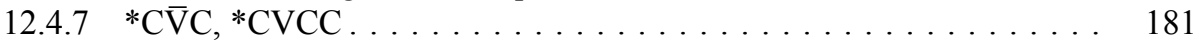

12.4.8 Statut syllabique de la consonne finale . . . . . . . . . . . . . . . . 182

12.4.8.1 C\# est coda ou intervocalique . . . . . . . . . . . 182

12.4.8.2 Situation en français . . . . . . . . . . . . . . . 183

12.4.9 Changement d'affiliation syllabique : consonification et vocalisation 183

12.5 Fonctionnement du changement diachronique . . . . . . . . . . . . . . . 184

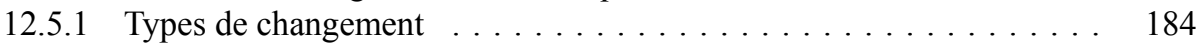

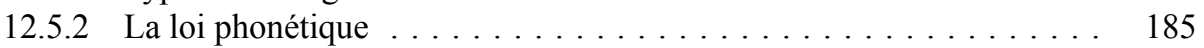

12.5.2.1 Le langage est un objet naturel . . . . . . . . . . . . 185

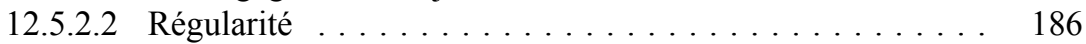

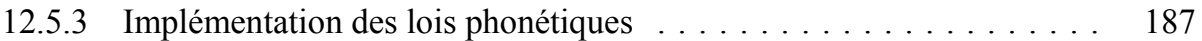

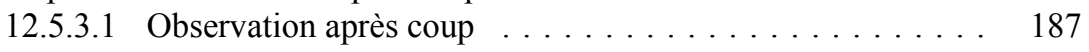

12.5.3.2 Observation des changements en cours . . . . . . . . 187 
12.5.3.3 Diffusion dans le corps social . . . . . . . . . . . . 188

12.5.3.4 Diffusion dans le corps lexical . . . . . . . . . . . . 188

a. La diffusion lexicale est réelle . . . . . . . . . . . . 188

b. Le changement néogrammairien est réel . . . . . . . . 190

12.5.3.5 Deux types de changement : d'en bas et d'en haut . . . . . 190

12.5.3.6 Variation inhérente à l'évolution . . . . . . . . . . . . . . . . 191

12.5.4 Variation dans la phonétique historique du français . . . . . . . . . 191

12.5.4.1 Facteurs internes et externes . . . . . . . . . . . . . . 191

12.5.4.2 Facteurs internes (évolution phonétique et son implémentation) . . . . . . . . . . . . . . 191

a. Idiosyncrasies avec et sans cause (pour l'observateur après coup $\ldots \ldots \ldots \ldots \ldots 1$

b. Idiosyncrasies lexicales qui ont une cause décelable . . . . . . . . . . . . . . . . . . 192

i. Mots savants . . . . . . . . . . . . . . 192

ii. Fréquence lexicale, statut grammatical . . . . . . . 193

c. Idiosyncrasies lexicales sans cause apparente . . . . . . 193

12.5.4.3 Facteurs externes (analogie et emprunt) . . . . . . . . . . . 193

a. Outils néogrammairiens incomplets et conséquences

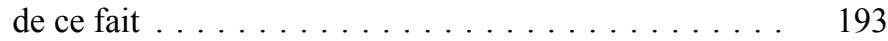

b. Abus de l'analogie . . . . . . . . . . . . . . . 194

c. Abus de l'emprunt (ou forme dialectale) . . . . . . . . 195

d. Abus de la loi phonétique . . . . . . . . . . . . . . 195

12.5.4.4 Comment identifier les causes de la variation . . . . . . . . 196

12.5.5 Naissance de l'innovation . . . . . . . . . . . . . . . . . . . . . . 196

12.5.5.1 La Parole fait évoluer la Langue . . . . . . . . . . . . . . . 196

12.5.5.2 Qui innove et pour quelle raison ? . . . . . . . . . . . . . 197

12.6 Conventions (abréviations, présentation des données) . . . . . . . . . . . . . . . 199

12.6.1 Principes . . . . . . . . . . . . . . . . . . . . . . . 199

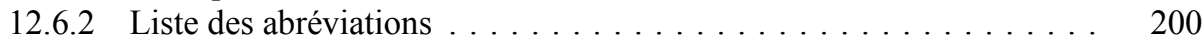

\section{Chapitre 13}

Processus non positionnels et réduction des mots (PS et TS) . . . . . . . . . . . . 203

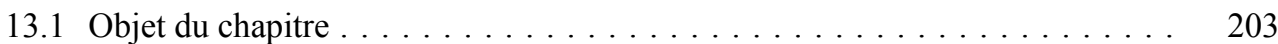

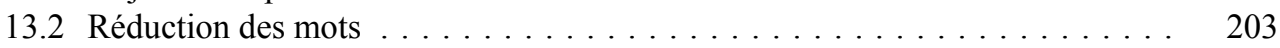

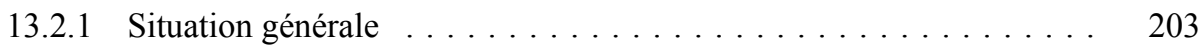

13.2.2 La syncope ........................ 203

13.2.2.1 Définition : tonique, atone (initiale, prétonique, posttonique,

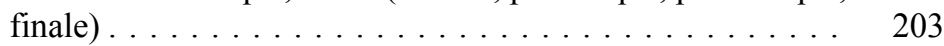

13.2.2.2 Centralisation et syncope . . . . . . . . . . . . . . . 204

13.2.2.3 Processus permanents . . . . . . . . . . . . . . 204

13.2.3 Consonification des voyelles non basses en hiatus . . . . . . . . . 205

13.2.4 Réduction des groupes triconsonantiques CCC. . . . . . . . . . . . . 207

13.2.4.1 Elimination de $\mathrm{C}_{2}$ et conditions de son maintien . . . . . . . 207

13.2.4.2 Substitution de la sonante dans les groupes CCR. . . . . . 210 


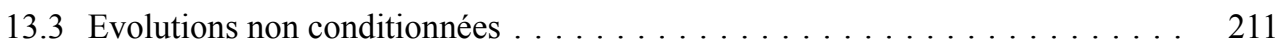

13.3.1 Place des évolutions non conditionnées dans l'organisation

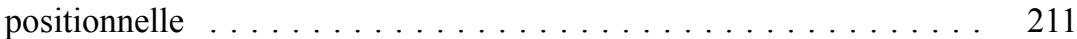

13.3.2 Evolutions vocaliques non conditionnées $\ldots \ldots \ldots \ldots \ldots \ldots .212$

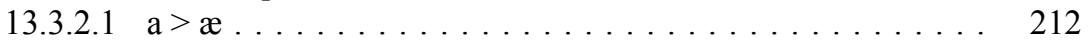

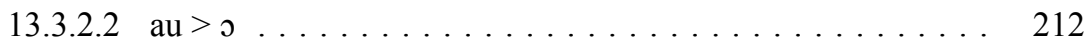

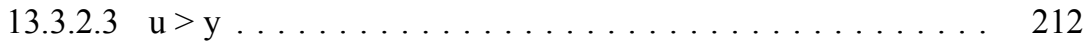

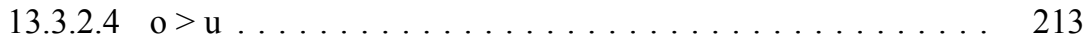

13.3.2.5 Emergence de la série des voyelles antérieures arrondies . . 213

13.3.2.6 Antériorisation générale du système vocalique ... . . . . 214

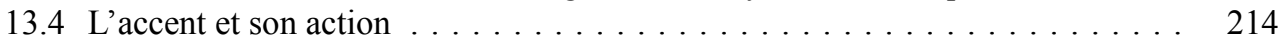

13.4.1 Nature et place de l'accent . . . . . . . . . . . . . . . 214

13.4.2 Changement de nature de l'accent entre le latin classique et le latin

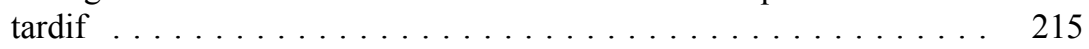

13.4.3 Conséquences du changement accentuel sur le système vocalique . . . 216

13.4.3.1 Ruine de la longueur lexicale et distinctive . . . . . . . . 216

13.4.3.2 Evolution triple du système vocalique du lc en lt . . . . . . 216

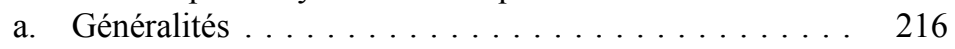

b. Voyelles toniques................ 216

c. Voyelles atones en syllabe fermée . . . . . . . . 216

d. Voyelles atones en syllabe ouverte . . . . . . . . 217

13.4.3.3 Diphtongaisons spontanées . . . . . . . . . . . . . . 217

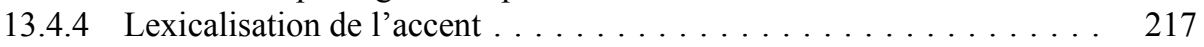

13.4.4.1 L'accent est stable parce qu'il est lexicalisé . . . . . . . 217

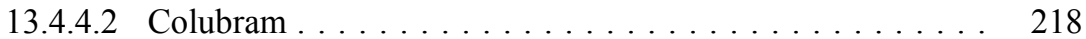

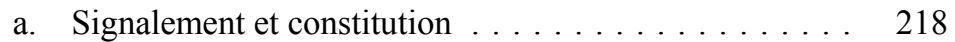

b. Analyse . . . . . . . . . . . . . . . . . . 219

13.4.4.3 Mulierem ...................... 220

13.4.5 Ruine de l'accent de longueur, avènement de l'accent indéterminé ... 221

13.5 Moteurs de la variation : syncope et diphtongaison romane . . . . . . . . 222

13.5.1 Locus de variation, débat néogrammairien . . . . . . . . . 222

13.5.2 Variation intrinsèque et générée par le croisement de deux processus 222

13.5.2.1 La diphtongaison romane : variation intrinsèque ....... 222

13.5.2.2 Illustration . . . . . . . . . . . . . . . . . 222

13.5.3 Syncope : variation fruit du croisement avec un autre processus . . . 223

13.5.3.1 Fonctionnement du croisement [processus $1 \mathrm{X}$ processus 2] 223

13.5.3.2 [syncope X processus $\mathrm{x}$ ] : illustration ........... 223

\section{Chapitre 14}

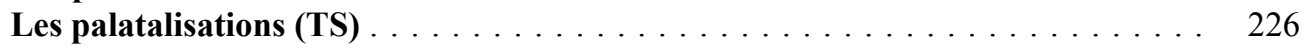

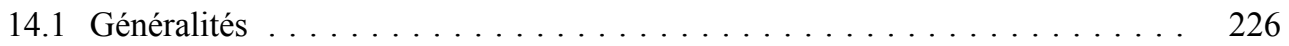

14.1.1 Trois palatalisations : romane, gallo-romane, $\mathrm{C}+\operatorname{yod} \ldots \ldots \ldots \ldots 226$

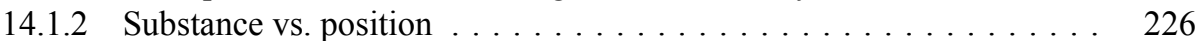

14.2 Palatalisation par une voyelle vs. par une consonne $\ldots \ldots \ldots \ldots \ldots \ldots 227$

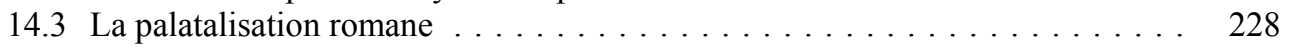

14.3.1 Aboutissements et caractérisation : asymétrie $\mathrm{k}-\mathrm{g} \ldots \ldots \ldots \ldots 228$ 


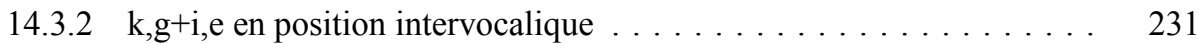

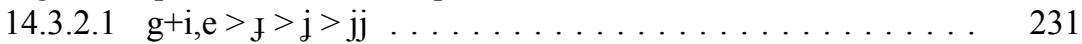

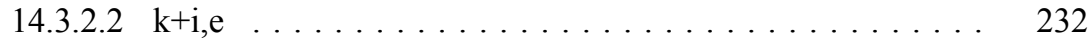

14.3.3 Dépalatalisation source de l'asymétrie et du dégagement de yod . . . 233

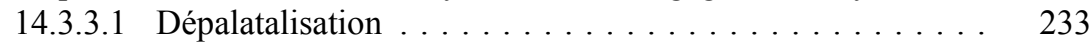

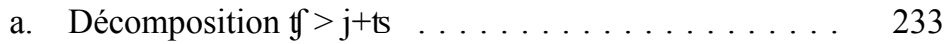

b. Décomposition $\left[c_{, f}\right]>\mathrm{j}+\mathrm{t}, \mathrm{d} \ldots \ldots \ldots 233$

c. Fonctionnement de la dépalatalisation : externalisation de la palatalité . . . . . . . . . . . . . . 234

d. Dépalatalisation cause du yod dégagé . . . . . . . . 235

14.3.3.2 Palatalisation romane : quatre processus successifs . . . . . 236

14.4 La palatalisation gallo-romane . . . . . . . . . . . . . . . . . 237

14.4.1 Evolution $: \mathrm{k}, \mathrm{g}+\mathrm{i}, \mathrm{e}, \mathrm{a}>\mathrm{t}, \mathrm{d} \mathrm{s} \ldots \ldots \ldots \ldots \ldots \ldots \ldots \ldots \ldots \ldots \ldots$

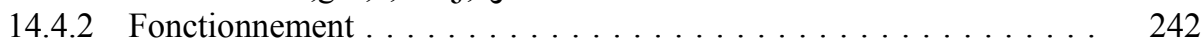

14.4.2.1 Palatalisations romane et gallo-romane : même

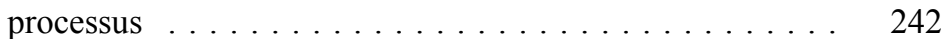

14.4.2.2 Indépendance de la palatalisation et de l'affrication . . . . 244

14.4.2.3 Avis reçus . . . . . . . . . . . . . . . . . . . 244

a. Avancement mécanique vers l'avant . . . . . . . . . 244

b. Asymétrie sourde sifflante $t s$ - voisée chuintante $d 3 \ldots 245$

c. Stade intermédiaire $[c, f]$ (occlusives palatales) . . . . 248

$14.5 \mathrm{k}, \mathrm{g}+(\mathrm{i}, \mathrm{e}): \mathrm{fac}(\mathrm{e}) \mathrm{re}, \operatorname{vinc}(\mathrm{e}) \mathrm{re} \ldots \ldots \ldots \ldots \ldots \ldots \ldots \ldots \ldots$

14.5.1 Particularité du paradigme . . . . . . . . . . . . . . . . 249

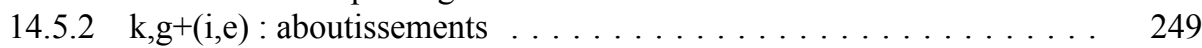

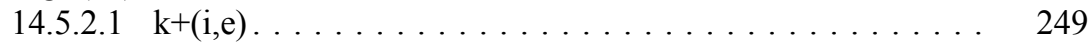

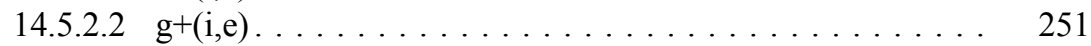

14.5.2.3 Résumé de la situation : responsabilité du $\mathrm{r} \ldots \ldots . \ldots 251$

14.5.2.4 Dépalatalisation de $[\mathrm{c}, \mathrm{f}]$ causée par l'intolérance de $\mathrm{r}$ pour

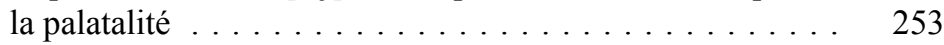

14.5.3 k,g+(i,e)+r appuyé : $\operatorname{vinc}(\mathrm{e}) \mathrm{re}, \operatorname{surg}(\mathrm{e}) \mathrm{re} \ldots \ldots \ldots \ldots \ldots \ldots \ldots$

$14.5 .4 \mathrm{k}, \mathrm{g}+(\mathrm{i}, \mathrm{e})+\mathrm{r}$ intervocalique $:$ facc(e)re, $\operatorname{rag}(\mathrm{e}) \mathrm{re} \ldots \ldots \ldots \ldots 255$

\section{Chapitre 15}

Yod (oral j et nasal $\tilde{\mathbf{j}})(\mathbf{T S}$ et PS) $\ldots \ldots \ldots \ldots \ldots \ldots \ldots$

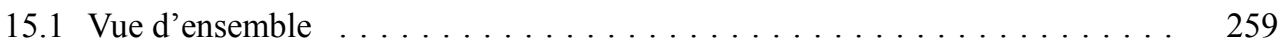

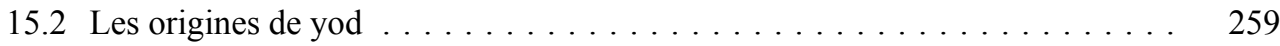

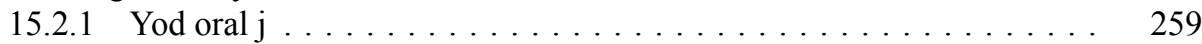

15.2.1.1 Yod hérité . . . . . . . . . . . . . . . . 259

15.2.1.2 Yod issu de la consonification de i,e en hiatus . . . . . . 260

15.2.1.3 Yod géminé issu $\mathrm{de}_{\mathrm{J}}<\mathrm{dj}, \mathrm{gj}, \mathrm{g}+\mathrm{i}$,e en position

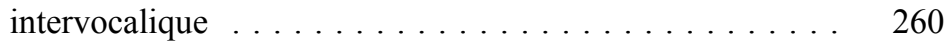

15.2.1.4 Yod géminé issu de lab+yod . . . . . . . . . . . . 261

15.2.1.5 Yod issu de la dépalatalisation . . . . . . . . . . 261

15.2.1.6 Yod issu de la trajectoire intrinsèque des vélaires $\mathrm{k}, \mathrm{g}$ spirantisées en $\mathrm{x}, \mathrm{\gamma} \ldots \ldots \ldots \ldots \ldots \ldots \ldots$ 
15.2.1.7 Yod issu de la consonification de i premier élément de diphtongue ..................... 261

a. $\underline{\text { ie }}>\mathrm{j} \underline{\varepsilon}$ (bascule des diphtongues) $\ldots \ldots \ldots \ldots 261$

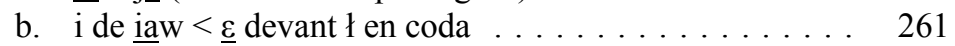

15.2.1.8 Yod épenthétique à l'intervocalique (anti-hiatique). . . . . . 262

15.2.2 Yod nasal $\tilde{j}$ : la nasale palatale $\mathrm{n}$ en coda . . . . . . . . . . . 262

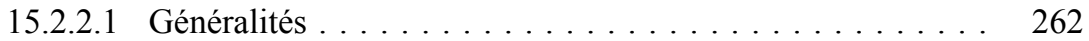

15.2.2.2 Origines de $\mathrm{n} \ldots \ldots \ldots \ldots \ldots \ldots \ldots \ldots$

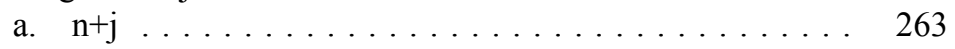

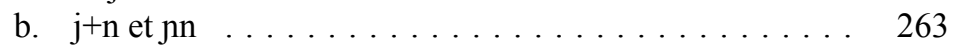

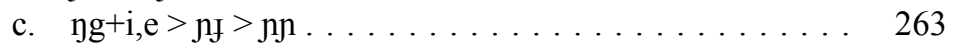

15.2.2.3 Origines de yod nasal $\tilde{\jmath} \ldots \ldots \ldots \ldots 263$

a. $\tilde{\mathrm{j}}$ issu de la dégémination de $\mathrm{n}$. . . . . . . . . . 263

b. $\tilde{j}$ issu de la rupture d'homorganicité de $\mathrm{y}+\mathrm{k}, \mathrm{g} \ldots \ldots . . .264$

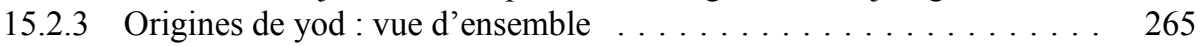

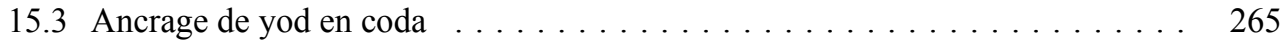

15.3.1 Palatalité dégagée à gauche et à droite . . . . . . . . . . . 265

15.3.2 Comportement du yod dégagé par les dépalatalisations et la métathèse 266

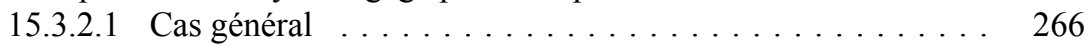

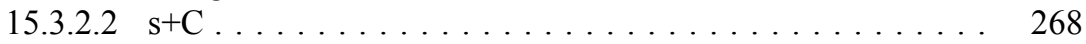

15.3.3 Analyse . . . . . . . . . . . . . . . . . . . . . 269

15.3.3.1 Ancrage de yod réussi en l'absence de coda . . . . . . . . . . . 269

15.3.3.2 Ancrage de yod bloqué en présence d'une coda . . . . . . 270

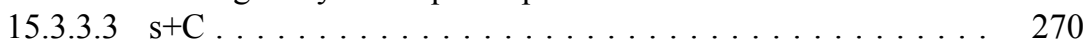

a. L'ancrage de yod provoque le branchement du s . . . . 270

b. sts $>$ ss : lénition intervocalique (spirantisation) . . . . 271

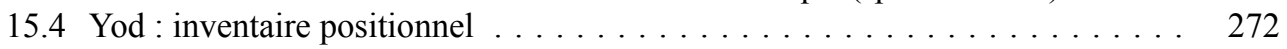

15.4.1 Les différents yods et de leur évolution : inventaire . . . . . . . . . . 272

15.4.1.1 Objet de la section . . . . . . . . . . . . . 272

15.4.1.2 Modification de la position de yod . . . . . . . . . . 272

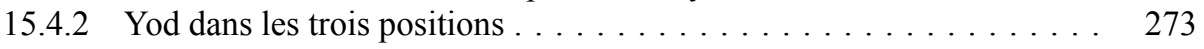

15.4.2.1 Yod (géminé) en position intervocalique . . . . . . . . 273

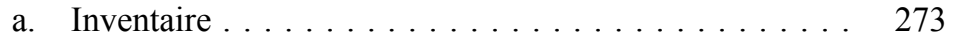

b. Evolution ultérieure de jj . . . . . . . . . . . 273

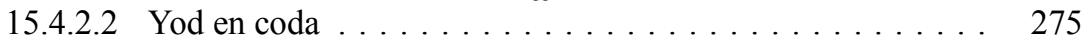

15.4.2.3 Yod en position forte . . . . . . . . . . . 276

15.4.2.4 Résumé : dégénérescence de yod dans la langue, renaissance en ancien français. . . . . . . . . . . . . . . . 277

\section{Chapitre 16}

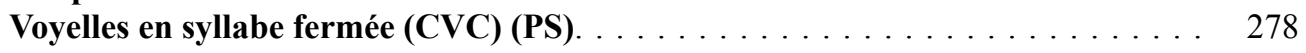

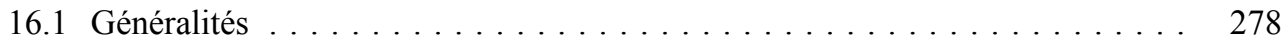

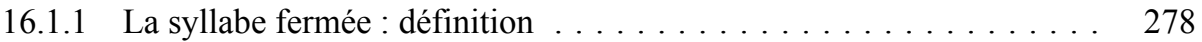

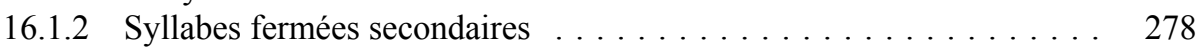

16.1.3 Distribution lacunaire des syllabes fermées . . . . . . . . . . . . . 279

16.1.4 Distribution des voyelles en syllabe fermée . . . . . . . . . . . . . . 279 
16.1.5 Evolutions vocaliques en syllabe fermée : généralités . . . . . . . . . . 279

16.1.5.1 Absence de syncope : maintien général . . . . . . . . . . . 279

a. Maintien des voyelles toniques en syllabe fermée . . . 279

b. Maintien des voyelles en syllabe fermée initiale . . . . 279

c. Maintien des voyelles en syllabe fermée prétonique . . 280

16.1.5.2 Absence de centralisation . . . . . . . . . . . . 281

16.1.5.3 Absence de diphtongaison spontanée . . . . . . . . . 281

16.1.5.4 Identité d'évolution en syllabe fermée pour les voyelles

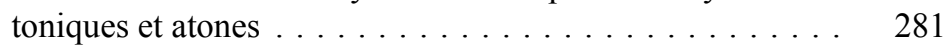

16.1.5.5 Stabilité fondamentale des voyelles en syllabe fermée . . . 282

16.1.6 Effets sur les voyelles consécutifs à la chute des consonnes en coda . 282

16.1.6.1 j et w en coda . . . . . . . . . . . . . . . . 282

a. Vocalisation de $\mathrm{j}$ et $\mathrm{w}$ en coda ............ 282

b. Action fermante de $\mathrm{j}$ et $\mathrm{w}$ en coda . . . . . . . . . . 282

16.1.6.2 Les nasales $n$ et $m$ en coda . . . . . . . . . . . . 283

a. Nasalisation . . . . . . . . . . . . . . . . 283

b. Action fermante des nasales . . . . . . . . . . . . . 284

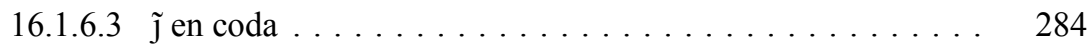

16.1.6.4 s en coda .............................. 284

16.1.7 $\underline{\varepsilon}$ et $\underline{\jmath}$ toniques en CVC $:$ diphtongaison conditionnée $\ldots \ldots \ldots \ldots 285$

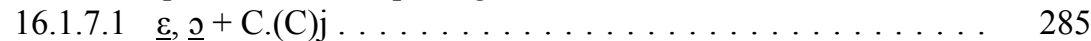

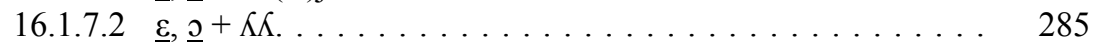

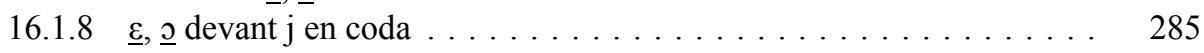

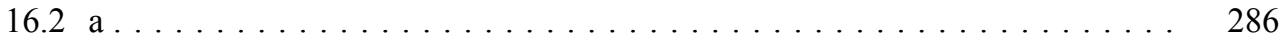

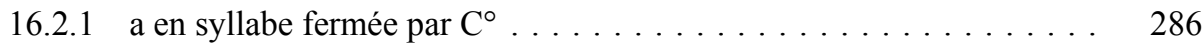

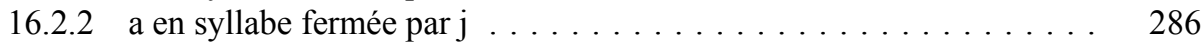

16.2.3 a en syllabe fermée par $n, \mathrm{~m}, \tilde{\mathrm{j}}, \mathrm{w}, \mathrm{s} \ldots \ldots \ldots \ldots \ldots \ldots$

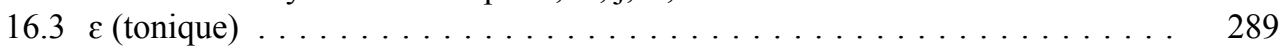

$16.3 .1 \quad \underline{\varepsilon}$ en syllabe fermée . . . . . . . . . . . . . . . . 289

16.3.2 Diphtongaison conditionnée de $\underline{\varepsilon} \ldots \ldots \ldots \ldots \ldots$. . . . . . . . . 289

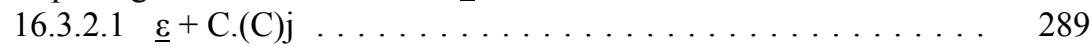

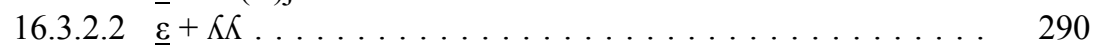

$16.3 .3 \underline{\varepsilon}$ en syllabe fermée $\operatorname{par} \mathrm{j} \ldots \ldots \ldots \ldots \ldots \ldots \ldots \ldots$

$16.3 .4 \underline{\varepsilon}$ en syllabe fermée par $\mathrm{n}$ ou $\mathrm{m} \ldots \ldots \ldots \ldots \ldots \ldots$

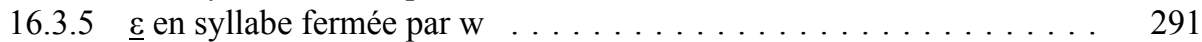

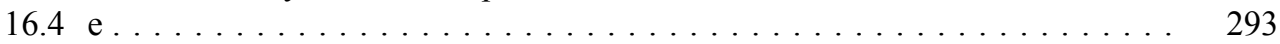

16.4.1 e en syllabe fermée $\operatorname{par} \mathrm{C}^{\circ} \ldots \ldots \ldots \ldots \ldots \ldots \ldots \ldots \ldots \ldots$

16.4.2 e en syllabe fermée par yod . . . . . . . . . . . . . . . . . 294

16.4.3 e en syllabe fermée par $\mathrm{n}, \mathrm{m}, \tilde{\mathrm{j}}, \mathrm{w} \ldots \ldots \ldots \ldots \ldots$

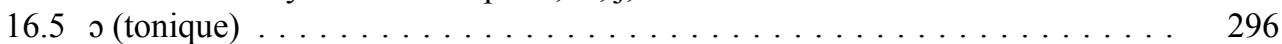

16.5 .1 o en syllabe fermée . . . . . . . . . . . . . . . . . . 296

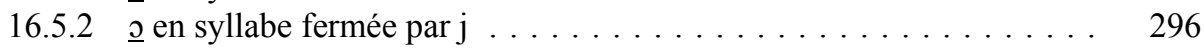

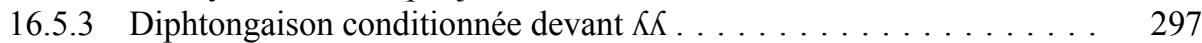

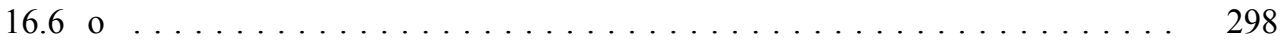

16.6.1 o en syllabe fermée $\operatorname{par} \mathrm{C}^{\circ} \ldots \ldots \ldots \ldots \ldots \ldots \ldots \ldots$

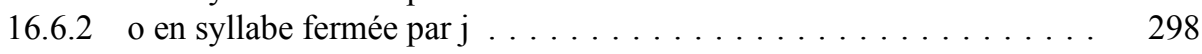

16.6.3 o en syllabe fermée par $\mathrm{n}, \mathrm{m}, \tilde{\mathrm{j}}, \mathrm{w} \ldots \ldots \ldots \ldots \ldots$ 


\section{Chapitre 17}

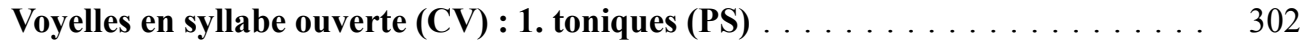

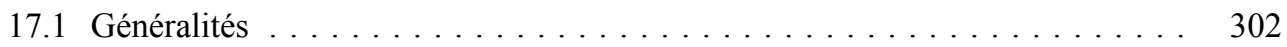

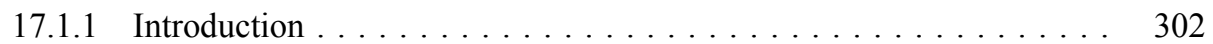

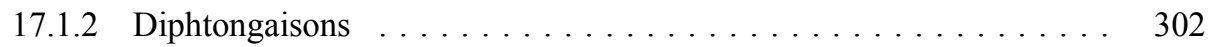

17.1.2.1 Diphtongaisons spontanées . . . . . . . . . . . 302

17.1.2.2 Diphtongues secondaires dites « de coalescence » . . . . . . 303

17.1.2.3 Monophtongaisons . . . . . . . . . . . . . . 303

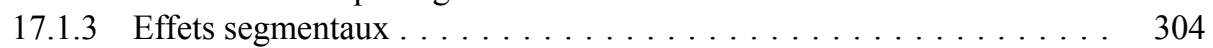

17.1.3.1 Effet Bartsch-Mussafia . . . . . . . . . . . . . . . . . . . . 304

17.1.3.2 Effet des nasales . . . . . . . . . . . . . . . . . . . . 305

17.1.3.3 Effet des labiales . . . . . . . . . . . . . . . . . 305

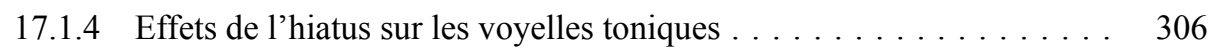

17.1.4.1 Généralités . . . . . . . . . . . . . . . . . . . . . 306

17.1.4.2 $\mathrm{V}$ en hiatus avec ə\#. . . . . . . . . . . . . . 306

17.1.4.3 $\underline{\mathrm{V}}$ en hiatus avec u\# et i\# . . . . . . . . . . . . . 306

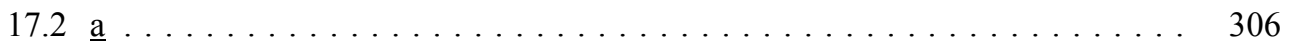

17.2.1 Evolution générale $\ldots \ldots \ldots \ldots \ldots \ldots \ldots \ldots \ldots \ldots \ldots \ldots$

17.2.2 $\underline{\mathrm{a}}+$ effet Bartsch-Mussafia $\ldots \ldots \ldots \ldots \ldots \ldots \ldots \ldots \ldots \ldots$

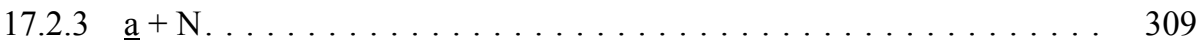

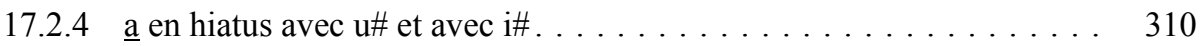

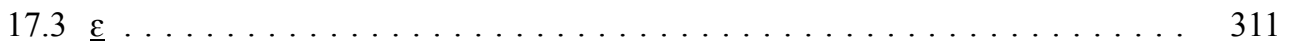

17.3.1 Evolution générale $\ldots \ldots \ldots \ldots \ldots \ldots \ldots \ldots \ldots \ldots \ldots \ldots \ldots \ldots$

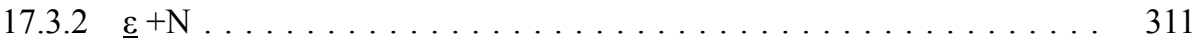

$17.3 .3 \varepsilon$ en hiatus avec u\#. . . . . . . . . . . . . . . . . 311

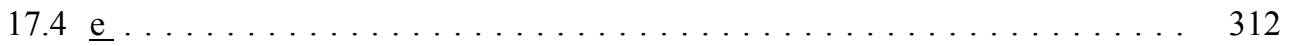

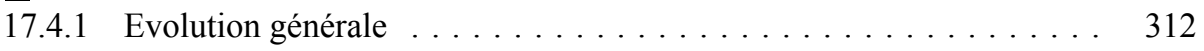

17.4.2 $\mathrm{e}+$ effet Bartsch-Mussafia $\ldots \ldots \ldots \ldots \ldots \ldots \ldots \ldots \ldots \ldots$

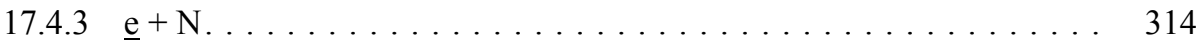

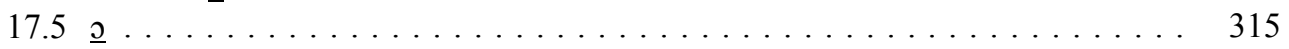

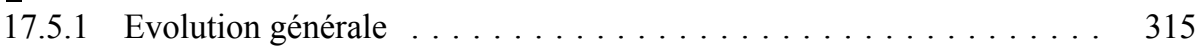

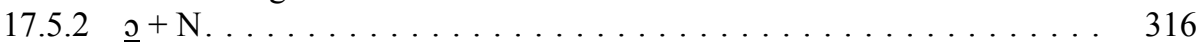

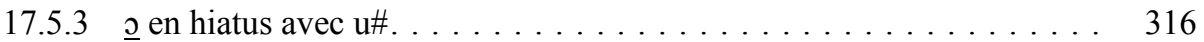

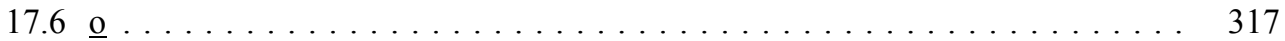

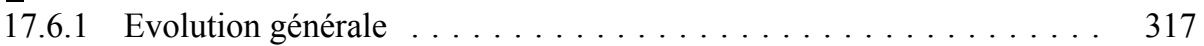

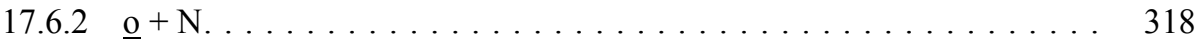

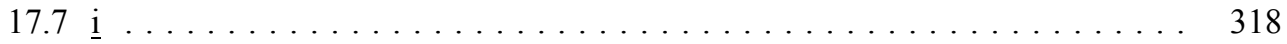

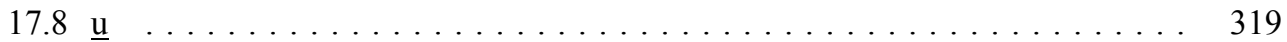

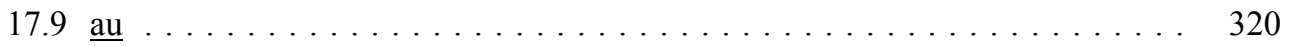




\section{Chapitre 18}

Voyelles en syllabe ouverte (CV) : 2. atones (PS)

18.1 Evolution en syllabe ouverte des voyelles atones du lc . . . . . . . . . . . . 321

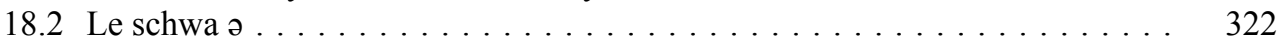

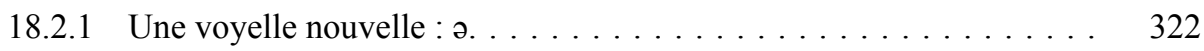

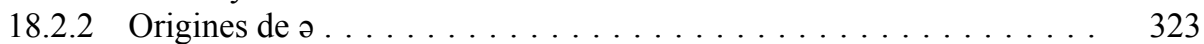

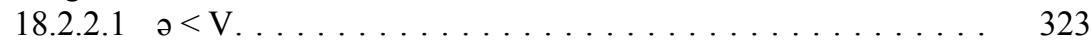

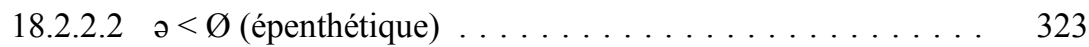

18.2.3 Chronologie des apparitions de $ə \ldots \ldots \ldots \ldots \ldots \ldots \ldots \ldots \ldots$

18.2.4 Deux évolutions différentes de $\partial: \partial^{1}$ et $\partial^{2} \ldots \ldots \ldots \ldots 24$

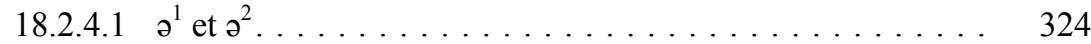

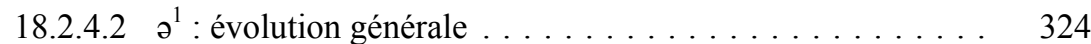

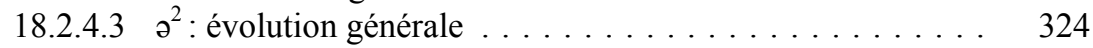

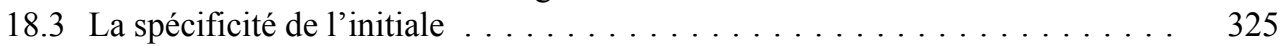

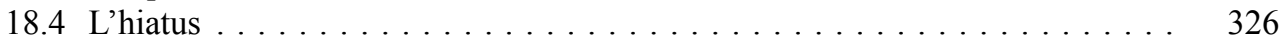

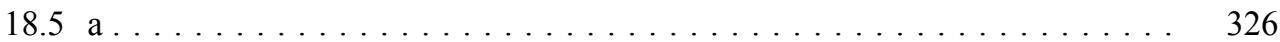

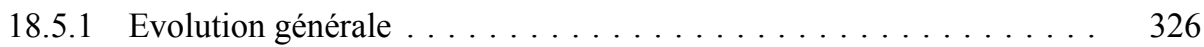

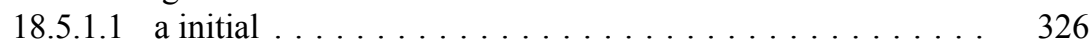

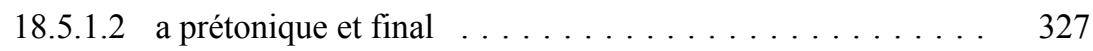

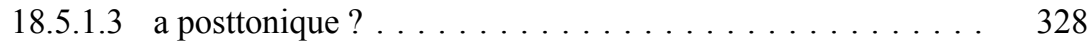

18.5.2 a initial précédé de consonne palatale $>\mathrm{e}$, d'où $\partial^{2} \ldots \ldots \ldots \ldots \ldots$

18.5 .3 a initial en hiatus avec $ø / \mathrm{y}>\mathrm{e}$, d'où $\partial^{2} \ldots \ldots \ldots \ldots \ldots$

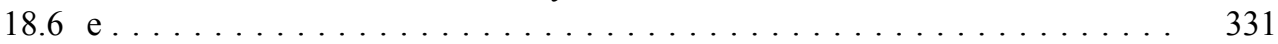

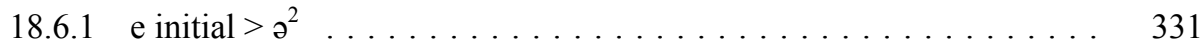

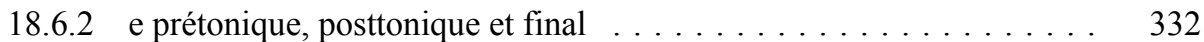

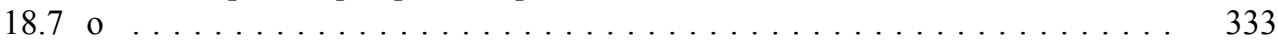

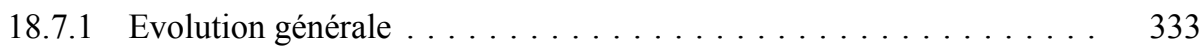

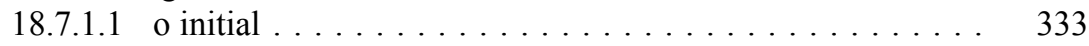

18.7.1.2 o prétonique, posttonique et final . . . . . . . . . 333

18.7.2 o initial $>$ e par dissimilation, d'où $\partial^{2} \ldots \ldots \ldots \ldots 34$

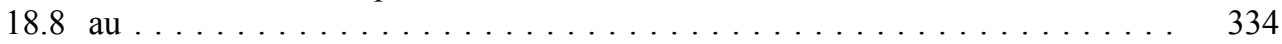

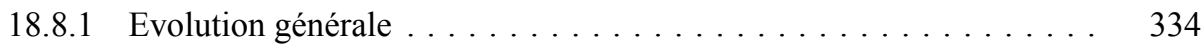

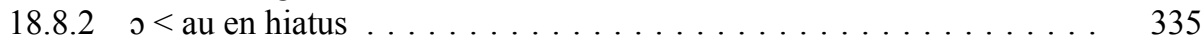

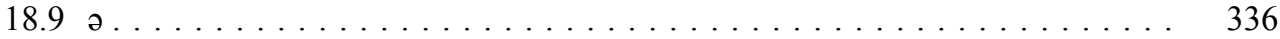

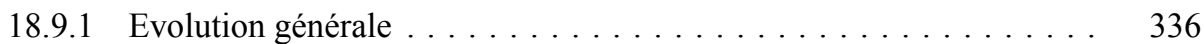

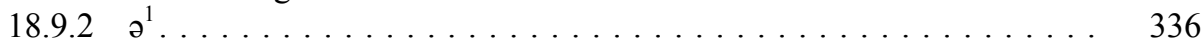

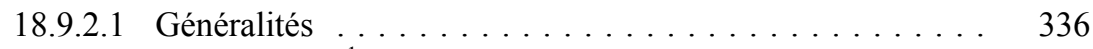

18.9.2.2 Maintien de $\partial^{1}$ prétonique ou final après TR . . . . . . . . 337

a. $\partial^{1}<\mathrm{e}, \mathrm{o}$,au prétonique ou final précédé d'un groupe TR 337

b. $\partial^{1}$ épenthétique $(<\varnothing)$ final après TR créé par la syncope 337

18.9.2.3 $\partial^{1}$ final (non précédé de TR) . . . . . . . . . . . . . . . . . . . . . 339

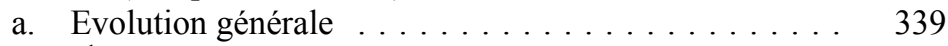

b. $\partial^{1}$ final $>\varnothing \ldots \ldots \ldots \ldots \ldots \ldots \ldots$

i. après consonne simple (intervocalique) . . . . . . 340

ii. après géminée . . . . . . . . . . . . . . . 340

iii. après groupes C.C « latins » . . . . . . . . . 341 
c. Maintien de $\partial^{1}$ final $\ldots \ldots \ldots \ldots \ldots \ldots \ldots \ldots \ldots$. . . . . . 342

i. après groupe $\mathrm{CCC} \ldots \ldots \ldots \ldots \ldots \ldots \ldots$

ii. après groupe C.C « non latins » . . . . . . . . 343

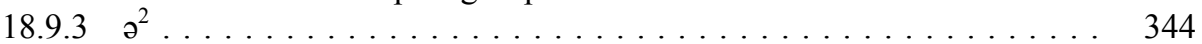

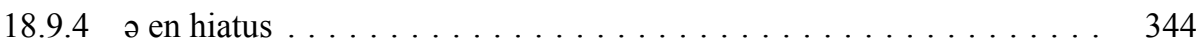

18.10 Evolution des atones en syllabe ouverte : essai de synthèse $\ldots \ldots \ldots \ldots .345$

\section{Chapitre 19}

Consonnes en Position Forte $\left(\{\#, \mathbf{C}\} \_\right)$: 1. obstruantes (TS) $\ldots \ldots \ldots \ldots .346$

19.1 Consonnes étudiées . . . . . . . . . . . . . . . . . . . . . . . 346

19.2 Obstruantes en position forte primaire $\ldots \ldots \ldots \ldots \ldots \ldots \ldots \ldots \ldots$

19.3 Obstruantes en position forte secondaire $\ldots \ldots \ldots \ldots \ldots \ldots \ldots \ldots \ldots . \ldots \ldots$

19.3.1 Fonctionnement général . . . . . . . . . . . . . . . . . . . . . 349

19.3.1.1 Position forte secondaire pré- ou posttonique . . . . . . . . 349

19.3.1.2 Trajectoires forte, faible et très faible . . . . . . . . . . . 349

a. Caractérisation ................. . 349

b. Effet de la trajectoire faible (et très faible) . . . . . 350

19.3.1.3 Locus de variation . . . . . . . . . . . . . . . 351

19.3.2 Labiales . . . . . . . . . . . . . . . . . . . . . 352

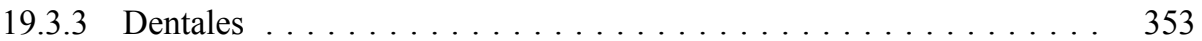

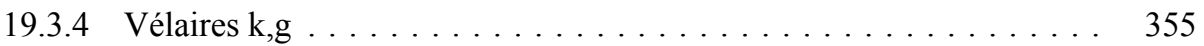

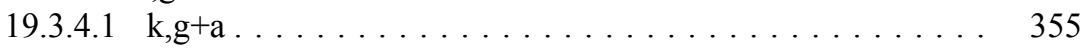

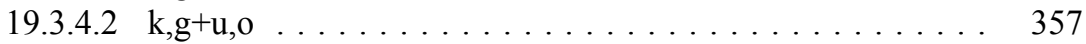

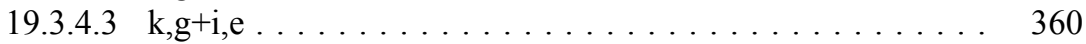

\section{Chapitre 20}

Consonnes en Position Forte $\left(\{\#, \mathbf{C}\} \_\right)$: 2. sonantes (TS) $\ldots \ldots \ldots \ldots \ldots 2$

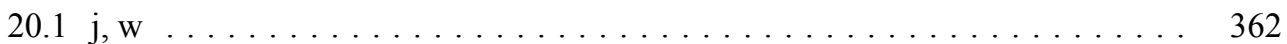

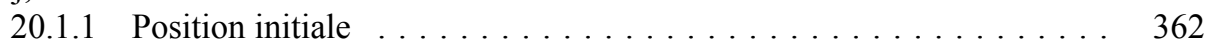

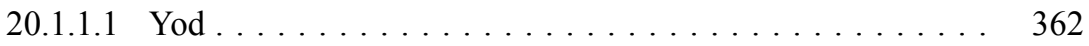

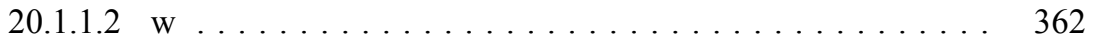

20.1.2 Yod appuyé $(\mathrm{C}+$ yod $) \ldots \ldots \ldots \ldots \ldots \ldots \ldots \ldots \ldots \ldots \ldots \ldots \ldots$

20.1.2.1 Fonctionnement général . . . . . . . . . . . . . 363

a. Processus latins $: \mathrm{dj}, \mathrm{gj}>\mathrm{J}, \mathrm{tj}>\mathrm{tsj} \ldots \ldots \ldots \ldots 363$

b. Position intervocalique . . . . . . . . . . . . . 364

c. Position appuyée ................. 364

d. C.j tardifs (mots savants et germaniques) . . . . . . . 365

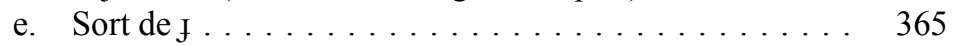

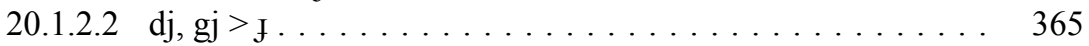

20.1.2.3 Assibilation $\mathrm{tj}>\mathrm{tsj} \ldots \ldots \ldots \ldots \ldots \ldots \ldots \ldots \ldots$

20.1.2.4 Palatalisation . . . . . . . . . . . . . . . . . . . . . 368

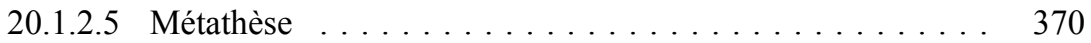

20.1.2.6 Labiale + yod : renforcement . . . . . . . . . . . . . . 373

20.1.2.7 Mots germaniques . . . . . . . . . . . . . . . . . 374 
20.1.2.8 Mots tardifs . . . . . . . . . . . . . . . 376

20.1.2.9 Emprunts au latin en ancien français : nouvelle métathèse . 376

20.1 .3 w appuyé $(\mathrm{C}+\mathrm{w}) \ldots \ldots \ldots \ldots \ldots \ldots \ldots \ldots \ldots$

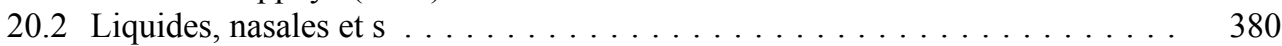

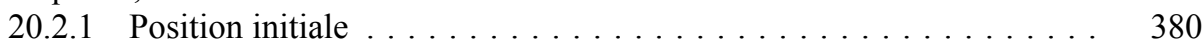

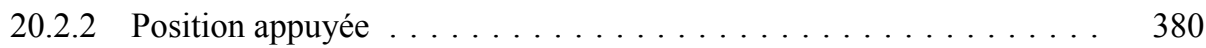

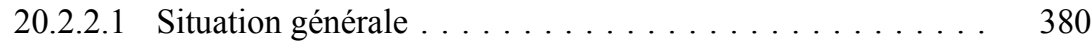

20.2.2.2 Epenthèse cam(e)ra > chambre ............ 383

\section{Chapitre 21}

Consonnes en coda $(\ldots$.C) $(\mathrm{TS}) \ldots \ldots \ldots \ldots \ldots \ldots \ldots \ldots$

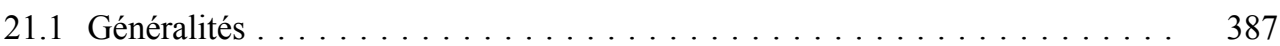

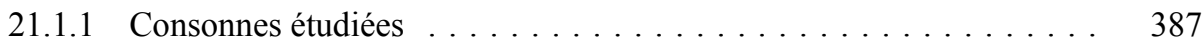

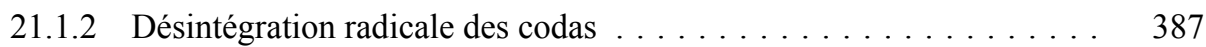

21.1.2.1 Mouvement général . . . . . . . . . . . . . . . 387

21.1.2.2 Coda différente de la consonne suivante $: \mathrm{C}_{\mathrm{x}} \cdot \mathrm{C}_{\mathrm{y}} \ldots \ldots \ldots 387$

21.1.2.3 Géminées $\mathrm{C}_{\mathrm{x}} \mathrm{C}_{\mathrm{x}} \ldots \ldots \ldots \ldots \ldots \ldots \ldots$

21.1.3 Reprise de la substance des codas par la voyelle précédente . . . . . 390

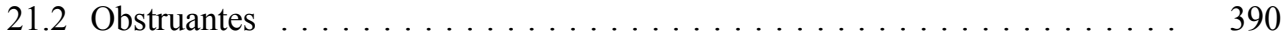

$21.2 .1 \quad$ Labiales . . . . . . . . . . . . . . . . . . . . . 390

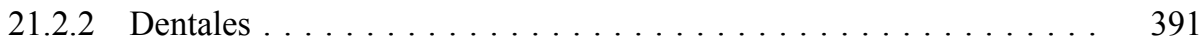

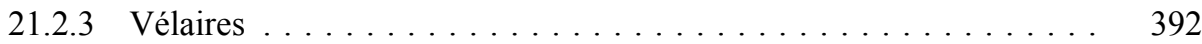

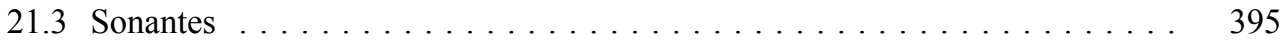

21.3 .1 Nasales . . . . . . . . . . . . . . . . . . . . . 395

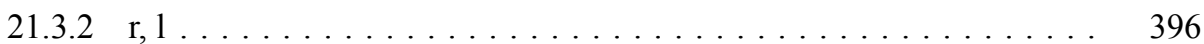

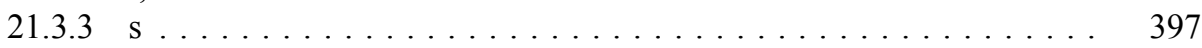

\section{Chapitre 22}

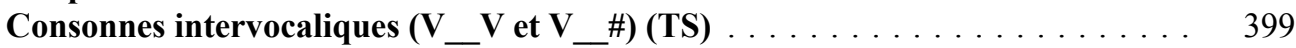

22.1 Consonnes étudiées : intervocaliques phonétiques et finales . . . . . . . . . . . 399

22.2 Statut syllabique de la consonne finale . . . . . . . . . . . . . . . . 399

22.2.1 Vue d'ensemble des diagnostics . . . . . . . . . . . . . . . . 399

22.2.2 Consonnes finales ..................... 400

22.2.2.1 Consonnes finales $\neq$ consonnes pré-consonantiques . . . . 400

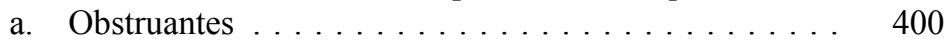

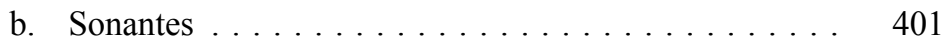

22.2.2.2 Consonnes finales $=$ consonnes phonétiquement

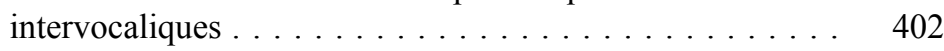

a. Obstruantes ...................... 402

b. Sonantes .................... 403

22.2.3 La voyelle tonique précédant la consonne finale est toujours libre . . . 403

22.2.3.1 Voyelle tonique devant consonne en position finale primaire 403

22.2.3.2 Voyelle tonique devant consonne en position finale secondaire 
22.3 Genèse de la liaison $\ldots \ldots \ldots \ldots \ldots \ldots \ldots \ldots \ldots \ldots \ldots . \ldots \ldots$

22.3.1 Chute des consonnes finales en sandhi externe à partir du $12^{\mathrm{e}}$ siècle 406

22.3.2 La consonne finale $\mathrm{C} \#$ devient coda à partir de la fin du $15^{\mathrm{e}}$ siècle . . 406

22.3.3 Genèse de la liaison en deux étapes : sandhi externe ( $12^{\mathrm{e}} \mathrm{s}$.), $\mathrm{C} \#$ coda

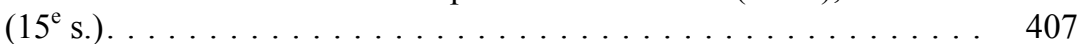

22.4 Intervocalique phonétique $V_{-} V_{\ldots} \ldots \ldots \ldots \ldots \ldots \ldots \ldots \ldots \ldots \ldots .409$

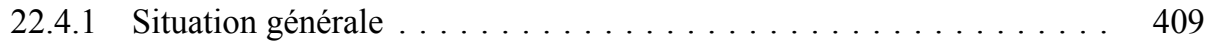

22.4.1.1 Action de la position et de la substance .......... . 409

22.4.1.2 Action de u,o adjacents (éliminant les labiales et vélaires) $\quad 410$

a. Variation en position intervocalique phonétique

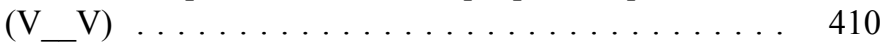

b. Variation devant u,o\# finaux promis à la chute .... . 412

22.4.2 Obstruantes .......................... 413

22.4.2.1 Labiales . . . . . . . . . . . . . . . . . . . . 413

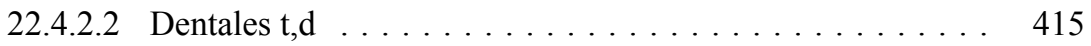

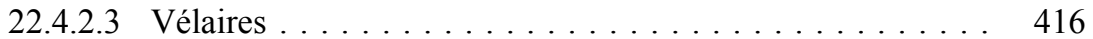

a. Vue d'ensemble ................ 416

b. $\mathrm{k}, \mathrm{g}+\mathrm{u}, \mathrm{o}(\mathrm{et} \mathrm{u}, \mathrm{o}+\mathrm{k}, \mathrm{g}) \ldots \ldots \ldots \ldots \ldots \ldots \ldots \ldots \ldots$

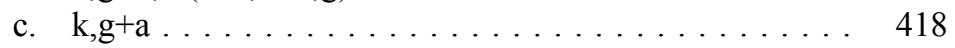

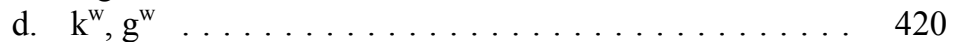

22.4 .3 Sonantes ............................ 421

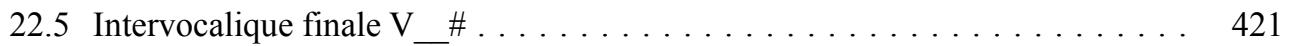

22.5.1 Dévoisement en finale . . . . . . . . . . . . . . . . 421

22.5.2 Position finale primaire $\mathrm{V}_{\ldots} \# \ldots \ldots \ldots \ldots \ldots \ldots \ldots \ldots \ldots .422$

22.5.2.1 Obstruantes . . . . . . . . . . . . . . . . . . . 422

22.5.2.2 Sonantes . . . . . . . . . . . . . . . . . . . . 423

a. Nasales. . . . . . . . . . . . . . . . . 423

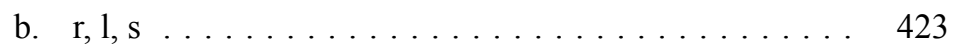

22.5.3 Position finale secondaire $V_{-}(\mathrm{V}) \# \ldots \ldots \ldots \ldots \ldots \ldots \ldots \ldots .424$

22.5.3.1 Obstruantes . . . . . . . . . . . . . . . . . . . . . 424

22.5.3.2 Sonantes . . . . . . . . . . . . . . . . . . . . 425

\section{Chapitre 23}

Consonnes en attaque branchante (muta cum liquida) (TS) . . . . . . . . . . 426

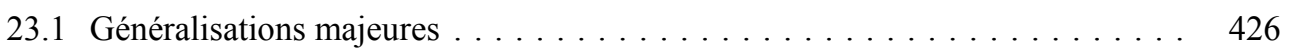

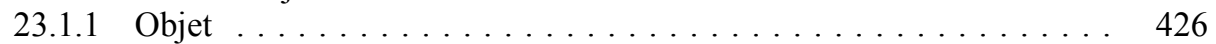

23.1.2 Communauté de destin de $\mathrm{T}$ seul et T dans TR . . . . . . . . . 426

23.1.3 Confusion des groupes primaires et secondaires . . . . . . . . . . 427

23.2 Grandes lignes de l'évolution . . . . . . . . . . . . . . . . . 428

23.2.1 Désolidarisation, confusion des groupes primaires et secondaires $\ldots 428$

23.2.2 Action de la coda (réduction des vélaires) . . . . . . . . . . . 431

23.2.3 Anaptyxe ........................... 431

23.2.4 Resolidarisation des groupes T.R hétérosyllabiques . . . . . . . . . 433

23.3 Attaques branchantes en position faible (intervocalique) $\ldots \ldots \ldots \ldots \ldots 433$

23.3.1 Vue d'ensemble . . . . . . . . . . . . . . . . . . 433 


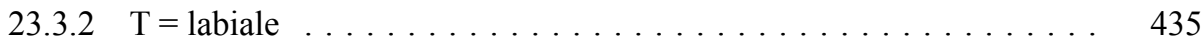

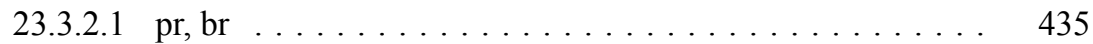

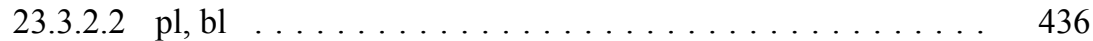

23.3.2.3 Groupes avec $w, f \ldots \ldots \ldots \ldots \ldots \ldots \ldots$

23.3.2.4 Vocalisation de la labiale $:$ bR $>$ w.R. . . . . . . . . 437

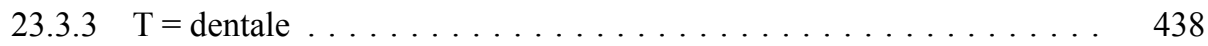

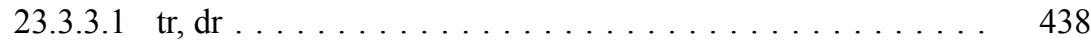

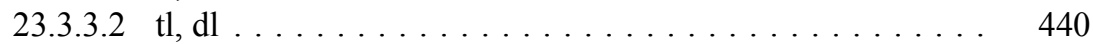

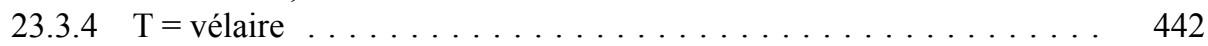

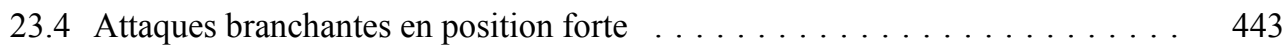

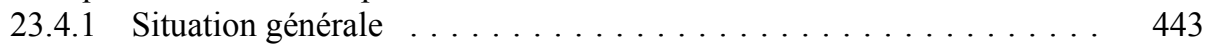

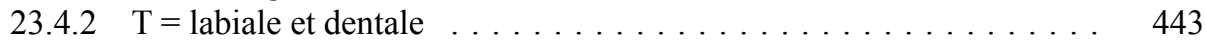

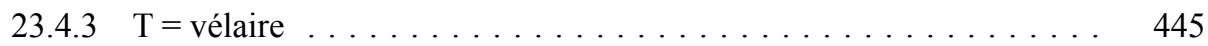

23.5 Groupes $\mathrm{Cj}, \mathrm{Cw}$ issus de la consonification au $13^{\mathrm{e}} \mathrm{s} . \ldots \ldots \ldots \ldots \ldots$

23.5.1 Evolution populaire au $13^{\mathrm{e}} \mathrm{s} . \ldots \ldots \ldots \ldots \ldots \ldots \ldots \ldots$

23.5.2 Action de la norme : hésitation entre le $13^{\mathrm{e}}$ et le $17^{\mathrm{e}}$ s. . . . . . 449

\section{Chapitre 24}

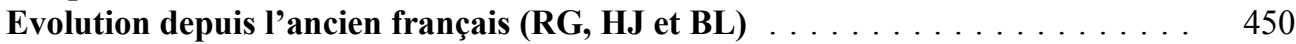

24.1 Plan du chapitre et généralités $(\mathrm{RG}$ et $\mathrm{HJ}) \ldots \ldots \ldots \ldots$. . . . . . . . . . . . . . . . . . . . . . .

24.2 La phonologie segmentale de l'ancien français $(\mathrm{RG}) \ldots \ldots \ldots \ldots$. . . . . . . . . . . . . . . . . . .

24.2.1 Les consonnes de l'ancien français ................ 451

24.2.1.1 Inventaire des consonnes de l'ancien français . . . . . . . 451

24.2.1.2 Processus qui touchent les consonnes . . . . . . . . . . . . 451

a. Modifications de l'inventaire ........... 451

b. Dévoisement des obstruantes en fin de mot . . . . . . 452

c. Amuïssement des consonnes en fin de mot et de radical 453

d. Réduction des consonnes en coda à l'intérieur des mots 454

e. Métathèse de la rhotique .............. 455

24.2.2 Les voyelles de l'ancien français ............... 455

24.2.2.1 Inventaire : monophtongues, diphtongues, triphtongue . . 455

24.2.2.2 Processus qui touchent les voyelles . . . . . . . . . . . 455

a. Suites de l'antériorisation gallo-romane du u . . . . . 455

b. Antériorisation et fermeture de a .......... 456

c. Le schwa .................... 456

i. La nature phonétique du schwa ......... 456

ii. Disparition du schwa final en hiatus (contextes limités $\ldots \ldots \ldots \ldots \ldots \ldots \ldots$. . . . . . . . 456

iii. Disparition du schwa interne (contexte limité) . . . 456

iv. Disparition du schwa en syllabe initiale (contexte limité $\ldots \ldots \ldots \ldots \ldots \ldots$. . . . . . . . . . . 456

d. L'épenthèse de e devant $\mathrm{sC}$ - à l'initiale de mot . . . . . . 457

e. Changements qualitatifs subis par les voyelles

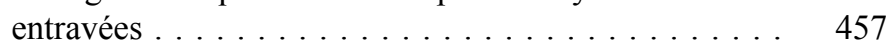

f. Longueur vocalique . . . . . . . . . . . . . . . 458 
g. Développement des diphtongues (y compris la

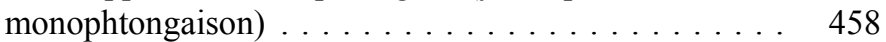

h. Diphtongaison dans le système morphologique ..... 460

i. Nasalisation et développement des voyelles nasales . . 461

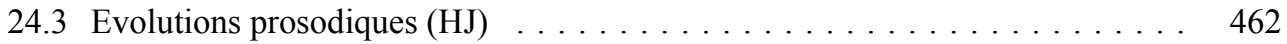

24.3.1 Accentuation. Vers une oxytonie stricte au $12^{\mathrm{e}}$ siècle . . . . . . . 462

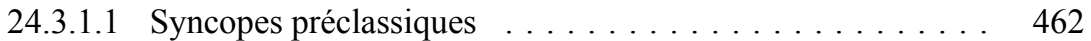

24.3.1.2 Syncopes en latin classique . . . . . . . . . . . . . . . 463

24.3.1.3 Apocope ........................ 463

24.3.1.4 Emprunts de la période de l'ancien français . . . . . . . . 464

24.3.2 Structure syllabique, début de l'ancien français $\ldots \ldots \ldots \ldots \ldots 468$

24.3.2.1 Nouveaux groupes CC\#. . . . . . . . . . . . . . . . . . 468

24.3.2.2 -s et -t flexionnels . . . . . . . . . . . . . . . . . . . . 469

24.3.2.3 Simplification des groupes en position finale . . . . . . . 469

24.3.3 Domaine d'accentuation : du mot à la phrase phonologique . . . . . 470

24.4 La phonologie segmentale du moyen français $(\mathrm{RG}) \ldots \ldots \ldots \ldots \ldots . .472$

24.4.1 Conditions externes de l'évolution entre le $14^{\mathrm{e}}$ siècle et le français

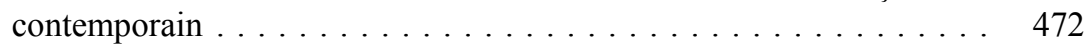

24.4.2 Les consonnes du moyen français . . . . . . . . . . . . 473

24.4.2.1 Inventaire des consonnes du moyen français . . . . . . . . 473

24.4.2.2 Processus qui touchent les consonnes . . . . . . . . . . . 473

a. Modifications de l'inventaire . . . . . . . . . . . . . 473

b. Glides . . . . . . . . . . . . . . . . 473

c. Perte des consonnes finales . . . . . . . . . . . 474

d. Distribution des consonnes . . . . . . . . . . . . . 475

24.4.3 Les voyelles du moyen français . . . . . . . . . . . . . . . . 475

24.4.3.1 Inventaire (monophtongues et diphtongues, orales et

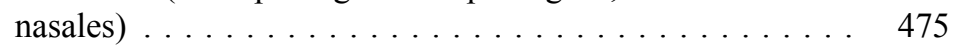

24.4.3.2 Processus qui touchent les voyelles . . . . . . . . . . . . 476

a. Monophtongues orales . . . . . . . . . . . 476

b. Schwa . . . . . . . . . . . . . . . . . 477

i. Nature phonétique du schwa . . . . . . . . . . . 477

ii. Disparition du schwa final . . . . . . . . . . . . . 477

iii. Chute du schwa interne . . . . . . . . . . . . . 477

iv. Développement du schwa en position initiale. . . . 478

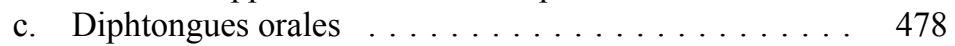

d. Monophtongues nasales . . . . . . . . . . . 478

e. Diphtongues nasales . . . . . . . . . . . . . . . 479

f. Dénasalisation devant nasale intervocalique . . . . . . 479

g. Longueur vocalique . . . . . . . . . . . . . . . . 480

24.5 La phonologie segmentale au début de la période du français moderne (env. 1600) (RG) . . . . . . . . . . . . . . . . . . . . . 481

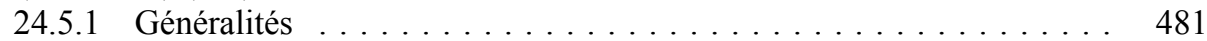

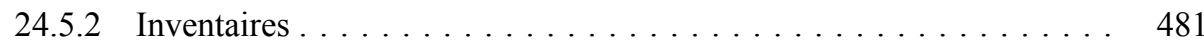

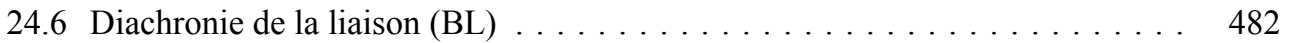

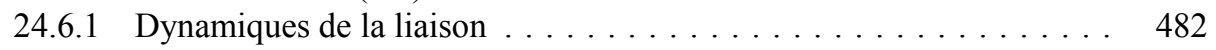

24.6.1.1 Dynamique de la syllabation ouverte . . . . . . . . . 483 
24.6.1.2 Dynamique du marquage morphologique . . . . . . . . . 483

24.6.1.3 Dynamique de l'enchaînement généralisé . . . . . . . . . . . 484

24.6.1.4 Dynamique de la graphie : le rôle de l'orthographe . . . . . 485

24.6.1.5 Variabilité systémique de la liaison . . . . . . . . . . . . . . . . . . . . . . . . . . 486

24.6.2 La liaison et sa variation . . . . . . . . . . . . . . . 486

24.6.2.1 Diachronie et variation diaphasique . . . . . . . . . . . . . . . 487

24.6.2.2 Diachronie et variation diastratique . . . . . . . . . . . . 488

24.6 .3 Conclusion . . . . . . . . . . . . . . . . . . . . . . . 489

\section{Partie 4}

Codes de l'écrit : Graphies et ponctuation (GP et YC) _ . . . . . . . . . . 491

\section{Chapitre 25}

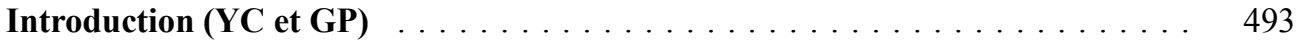

25.1 Pourquoi traiter des graphies dans une grammaire du français ? . . . . . . . . . . . 493

25.2 Historiographie : historiens de l'orthographe et éditeurs de textes . . . . . . . . 494

25.2.1 Orthographe et histoire de la langue . . . . . . . . . . . . . 494

25.2.2 Écrire une histoire de l'orthographe française . . . . . . . . . . . . 495

25.2.3 Histoire de l'orthographe et tentatives de réforme . . . . . . . . . . . 497

25.2.4 Pratiques éditoriales. La graphie comme voie d'accès à la phonie ? . . 498

25.2.5 Une histoire du code graphique dans la Grande Grammaire

Historique du Français (GGHF) . . . . . . . . . . . . . . . . . . . . . 499

25.2.6 Définition du corpus : une hétérogénéité nécessaire . . . . . . . . . 499

\section{Chapitre 26}

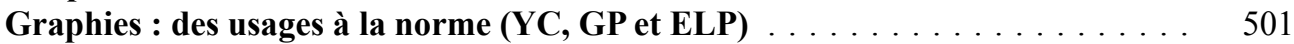

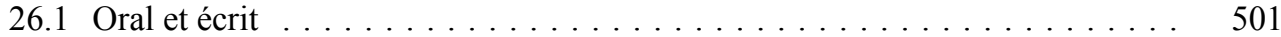

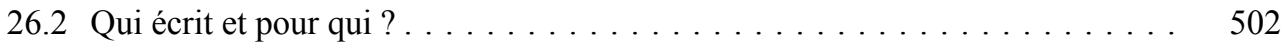

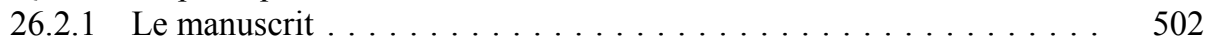

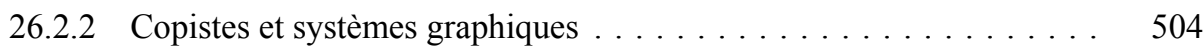

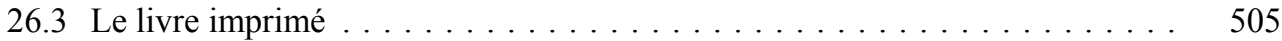

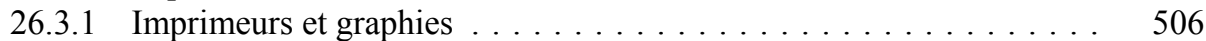

26.3.2 Les écrivains et les choix graphiques . . . . . . . . . . . . . 508

26.3.3 Destinataires de l'écrit : la lecture et les lecteurs . . . . . . . . . 508

26.3.4 Ateliers, chancelleries, Académie, École . . . . . . . . . . . . . . . 509

26.3.5 Choix graphiques et écriture : l'influence du graphétique . . . . . . 510

26.3.6 Au-delà de l'écriture : mise en page et oralisation . . . . . . . . . 511

26.4 L'alphabet latin pour une langue romane . . . . . . . . . . . . . . . 512

26.5 Les graphies dans les manuscrits du Moyen Age . . . . . . . . . . . . . . . . . . 513

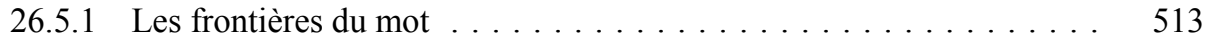

26.6 Les paramètres du diasystème médiéval $\ldots \ldots \ldots \ldots \ldots \ldots \ldots \ldots \ldots$

26.6.1 Variation diatopique, diaphasique et diastratique . . . . . . . . . 517

26.6.2 Variations individuelles et système ................ 519

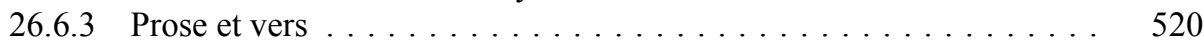


26.7 De la pratique à la norme prescriptive : la fabrique de l'orthographe . . . . . . 521

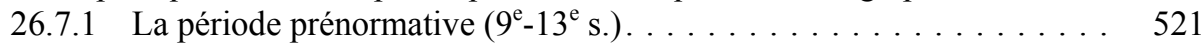

26.7.2 Premiers discours normatifs : les traités orthographiques du moyen

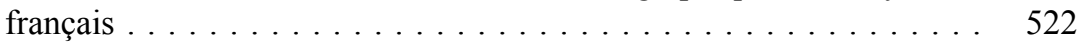

26.7.2.1 La structure des traités . . . . . . . . . . . . . . . 522

26.7.2.2 Une description raisonnée des usages . . . . . . . . . . . . . . 523

26.7.2.3 Un « bon usage » orthographique . . . . . . . . . . . . . . 524

26.7.2.4 La « concordance » avec le latin . . . . . . . . . . . . . 525

26.7.2.5 Les destinataires des traités du moyen français . . . . . . . . . . . 526

26.7.3 Orthographes anciennes et orthographes réformées . . . . . . . . . . . . . 527

26.7.3.1 Les nouveaux signes d'imprimerie . . . . . . . . . . . . 527

26.7.3.2 Palsgrave et les premières propositions . . . . . . . . . . . 527

26.7.3.3 Geoffroy Tory, le Champ fleury et la Briefve doctrine . . . . 528

26.7.3.4 Jacques Dubois et la lettre suscrite . . . . . . . . . . . 531

26.7.3.5 Les « bâtisseurs d'orthographe » . . . . . . . . . . . 533

a. Louis Meigret . . . . . . . . . . . . . . . . . 534

b. Jacques Peletier du Mans . . . . . . . . . . . . . 534

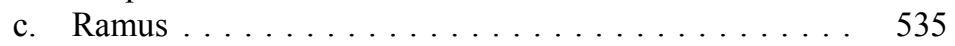

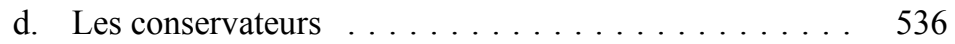

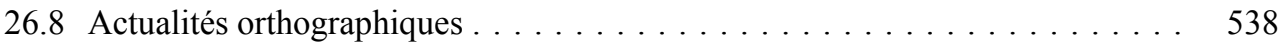

26.8.1 Les Rectifications de 1990 et la tolérance orthographique . . . . . . . . 538

26.8.1.1 Règles de l'orthographe rectifiée . . . . . . . . . . . . . . . . . . . . . 539

a. Principes généraux ... . . . . . . . . . . . . . . 539

b. Le trait d'union . . . . . . . . . . . . . 540

i. Mots composés : suppression du trait d'union .... 540

ii. Les numéraux : extension du trait d'union ..... . 541

c. Orthographe grammaticale ............. 541

i. Singulier et pluriel des noms composés ...... . 541

ii. Le pluriel des emprunts . . . . . . . . . . . . . . . . 542

iii. Le participe passé du verbe laisser . . . . . . . . . 542

d. Le tréma et les accents . . . . . . . . . . . . . . . 542

i. Le tréma . . . . . . . . . . . . . . . . . . . 542

ii. Accent grave sur $e \ldots \ldots \ldots \ldots \ldots$. . . . . . . . . . . . . . . . . . . . 543

iii. Accent aigu sur $e \ldots \ldots \ldots \ldots \ldots$. . . . . . . . 543

iv. Accent circonflexe . . . . . . . . . . . . . . . . . . 543

e. Les verbes terminés en -eler et -eter . . . . . . . . . 544

f. Rectification d'autres anomalies ... . . . . . . . . 545

g. Recommandations générales pour les néologismes et

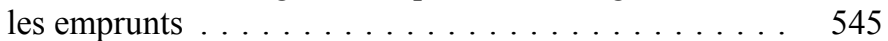

26.8.1.2 Institutionalisation des Rectifications . . . . . . . . . . . 545

26.8.2 Les scriptures électroniques . . . . . . . . . . . . . . . 546

26.8.2.1 Des contraintes venues du support . . . . . . . . . . . . . 546

26.8.2.2 Les procédés de l'écriture SMS . . . . . . . . . . . . . 546

26.8.2.3 Alternances de code . . . . . . . . . . . . . . . . . . . 548

26.8.2.4 Les facteurs de lisibilité . . . . . . . . . . . . . . . . . . 548

26.8.2.5 Apprentissage de la norme et variation . . . . . . . . . . 549 


\section{Chapitre 27}

Graphématique et graphétique en diachronie : les principaux phénomènes

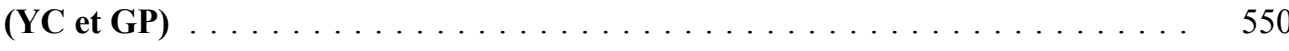

27.1 Les digraphes et leur utilisation en diachronie . . . . . . . . . . . . . . . . . 550

27.1.1 La double origine des digraphes . . . . . . . . . . . 550

27.1.2 Les premiers digraphes : la notation des phonèmes consonantiques . . 551

27.1.2.1 Les notations de la palatalité . . . . . . . . . . . . 552

27.1.3 La notation des phonèmes vocaliques $\ldots \ldots \ldots \ldots \ldots 53$

27.1.3.1 Les graphies historiques d'une ancienne diphtongue . . . . 553

27.1.3.2 Le digraphe est la marque d'un ancien hiatus . . . . . . . . . . . . 554

27.1.3.3 La vocalisation de $l$ antéconsonantique . . . . . . . . . . 554

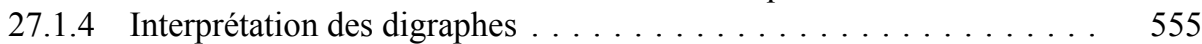

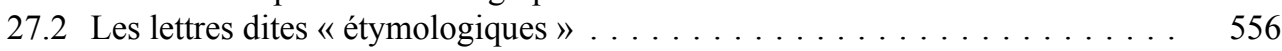

27.2.1 Une mutation du code graphique . . . . . . . . . . . . 557

27.2.1.1 Les causes du changement . . . . . . . . . . . . 558

27.2.1.2 La fin de la syllabe : une place muette pour une information nouvelle sur le mot . . . . . . . . . . . . . . . 558

27.2.1.3 Fonction diacritique ................ 559

27.2.1.4 La distinction des homophones, vers la logographie . . . . 560

27.2.1.5 L'organisation du lexique . . . . . . . . . . . . . . . . 560

27.2.1.6 La régulation des graphies . . . . . . . . . . . . . 561

27.2.2 Adossement au proto-système du latin . . . . . . . . . . . . . 562

27.2.2.1 Lien avec la phonographie . . . . . . . . . . . 562

27.2.3 Les causes de l'éviction partielle des lettres étymologiques . . . . . . . 563

27.2.3.1 Les défenseurs du phonocentrisme . . . . . . . . . . . . 563

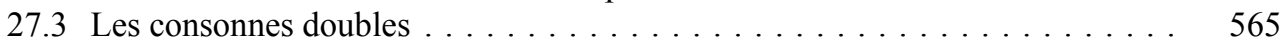

27.3.1 Un point névralgique dans le code graphique du français . . . . . . . 565

27.3.2 Les consonnes doubles en latin et la simplification en latin parlé tardif 566

27.3.3 Les consonnes doubles en ancien français . . . . . . . . . . . . 567

27.3.3.1 Fonction logographique . . . . . . . . . . . . . . 567

27.3.3.2 Fonction phonographique . . . . . . . . . . . 567

27.3.4 Les consonnes doubles en moyen français et en français moderne . . 568

27.3.4.1 Un procédé purement graphique . . . . . . . . . . . . 568

27.3.4.2 Valeur phonographique contextuelle .......... 568

27.3.4.3 Concurrence d'autres systèmes diacritiques : les accents .. 569

27.3.4.4 Fonction morphographique ............ 570

27.3.5 Le plurisystème : lettres étymologiques, consonnes doubles et

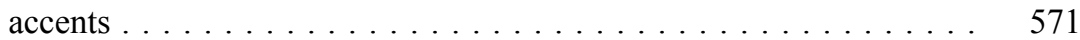

27.3.5.1 Les étapes d'une rationalisation . . . . . . . . . . . 571

27.3.6 La réarticulation des consonnes doubles et le cas de la gémination . . 571

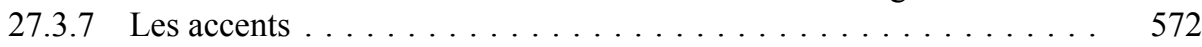

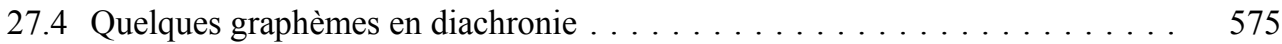

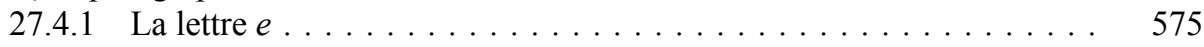

27.4.1.1 Sous-différenciation du code graphique médiéval ou surnorme orthographique moderne $\ldots \ldots \ldots \ldots \ldots 76$

27.4.1.2 Quel contexte pour le code graphique $\ldots \ldots \ldots . \ldots . \ldots 576$ 


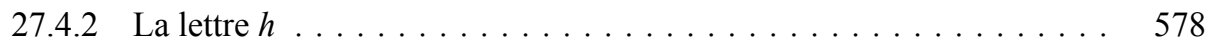

$27.4 .2 .1 \quad h$ initial . . . . . . . . . . . . . . . 579

27.4.2.2 $h$ composant de digraphe ............. 581

27.4.2.3 $h$ disjoncteur, marque de la frontière syllabique ou diacritique ........................... 582

27.4.2.4 $h$ comme marque de l'interjection $\ldots \ldots \ldots 58 \ldots \ldots . \ldots 53$

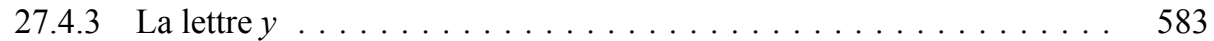

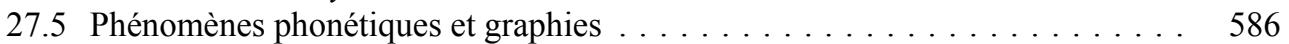

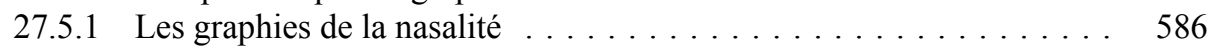

27.5.1.1 La nasalisation des voyelles au Moyen Age . . . . . . . . . . 586

27.5.1.2 Les premières graphies de la nasalité . . . . . . . . . 587

27.5.1.3 La dénasalisation partielle . . . . . . . . . . . . . 588

27.5.1.4 Chronologie, norme et variation . . . . . . . . . . . . 589

\section{Chapitre 28}

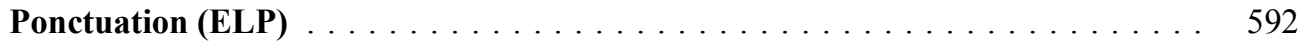

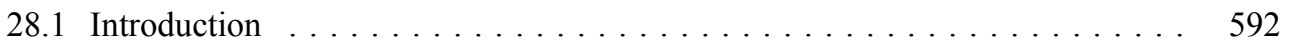

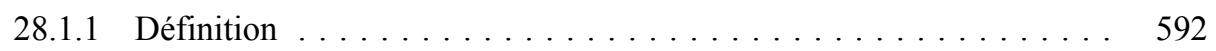

28.1.2 Graphématique diachronique et ponctuation . . . . . . . . . 593

28.1 .3 Signes et fonctions . . . . . . . . . . . . . . . . . . . . . 594

28.1.3.1 Graphies du mot et ponctuation du mot . . . . . . . . . . . . 594

a. Graphèmes alphabétiques ou segmentaux . . . . . . . . 594

b. Graphèmes suprasegmentaux ou signes de ponctuation du $\operatorname{mot} \ldots \ldots \ldots \ldots \ldots \ldots$. . . . . . . . . 594

28.1.3.2 Ponctuation de l'énoncé . . . . . . . . . . . . . . . . 594

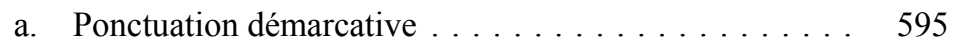

b. Ponctuation énonciative .............. 595

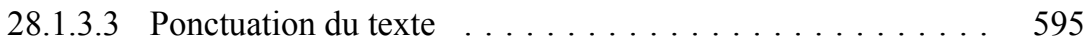

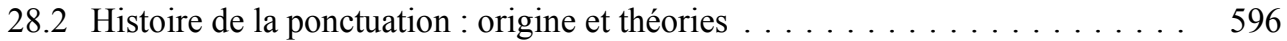

28.2.1 Origine des signes de ponctuation . . . . . . . . . . . . . 596

28.2.2 La ponctuation dans les manuscrits . . . . . . . . . . . . . . . 597

28.2.3 La ponctuation dans les imprimés . . . . . . . . . . . . . . . . 598

28.2.4 Tableau des signes de ponctuation en diachronie . . . . . . . . . . . . . 599

28.3 Histoire de la ponctuation $:$ signes et fonctions $\ldots \ldots \ldots \ldots$

28.3.1 Graphie et ponctuation du mot . . . . . . . . . . . . . 600

28.3.1.1 Graphèmes alphabétiques ou segmentaux du mot (accents, majuscules, graphie du nom propre) . . . . . . . . . . . 600

a. Graphèmes accentués . . . . . . . . . . . . . 600

b. Écriture du nom propre et opposition majuscule / minuscule . . . . . . . . . . . . . . . . 600

28.3.1.2 Graphèmes suprasegmentaux ou signes de ponctuation du mot (séquenciation, apostrophe, trait de division, trait d'union $\ldots \ldots \ldots \ldots \ldots \ldots$. . . . . . . . . . . . 601

a. Le blanc et la séquenciation des mots . . . . . . . . . 601

b. L'apostrophe et la séquenciation des mots . . . . . . . 602

c. Le trait d'union et le trait de division . . . . . . . . . . 602 
28.3.2 Ponctuation de l'énoncé $\ldots \ldots \ldots \ldots \ldots \ldots \ldots \ldots \ldots \ldots . \ldots \ldots 2$

28.3.2.1 Ponctuation démarcative $\ldots \ldots \ldots \ldots \ldots \ldots \ldots . \ldots 2$

28.3.2.2 Ponctuation rythmique et ponctuation syntaxique en ancien et moyen français . . . . . . . . . . . . . . . 603

a. Ponctuation rythmique . . . . . . . . . . . 603

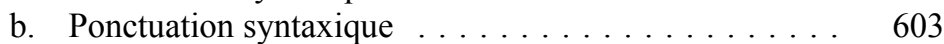

28.3.2.3 Théories et pratiques au $16^{\mathrm{e}} \mathrm{s}$. . . . . . . . . . . . . . 604

28.3.2.4 Théories et pratiques aux $17^{\mathrm{e}}$ et $18^{\mathrm{e}} \mathrm{s} \ldots \ldots \ldots \ldots \ldots .607$

28.3.2.5 Français moderne et contemporain . . . . . . . . . . 608

28.3.3 Ponctuation et modalités énonciatives : les rapports oral / écrit . . . . 609

28.3.3.1 Ancien français et moyen français . . . . . . . . . . . . . 609

28.3.3.2 Français préclassique et français classique . . . . . . . . 610

28.3.3.3 Français moderne et français contemporain . . . . . . . 611

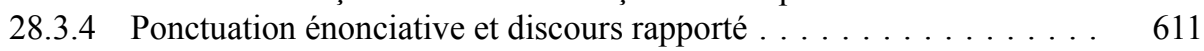

28.3.4.1 Ancien français et moyen français . . . . . . . . . . . 612

a. Signes de ponctuation syntaxique ou démarcative .... 612

b. Rubriques énonciatives . . . . . . . . . . . 612

28.3.4.2 Français préclassique et français classique . . . . . . . 613

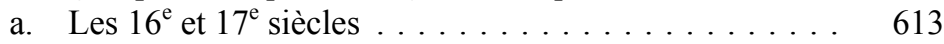

b. Le $18^{\mathrm{e}}$ siècle . . . . . . . . . . . . . . . 613

28.3.4.3 Français moderne et français contemporain . . . . . . . . . 613

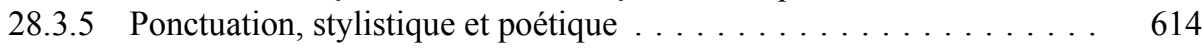

\section{Partie 5}

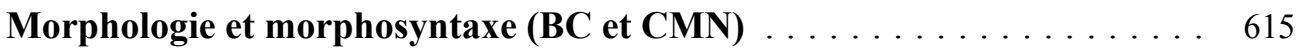

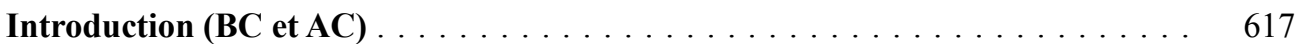

Le marquage morphologique des relations syntaxiques $\ldots \ldots \ldots \ldots \ldots \ldots .617$

« Head-marking » $:$ le système des clitiques . . . . . . . . . . . . . . . . . . . 618

« Dependent-marking » : le rôle des prépositions $\ldots \ldots \ldots \ldots \ldots \ldots \ldots \ldots .618$

La spécialisation de la catégorisation morphosyntaxique $\ldots \ldots \ldots \ldots \ldots \ldots 620$

\section{Chapitre 29}

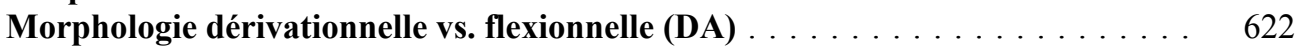

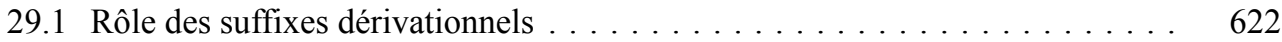

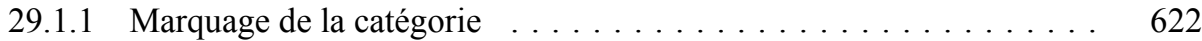

29.1.2 Marquage du genre pour les noms suffixés . . . . . . . . . 623

29.1.2.1 Les noms à référence non humaine . . . . . . . . . . . . 623

29.1.2.2 Les noms à référence humaine . . . . . . . . . . . . . 624

29.1.2.3 Changement de genre . . . . . . . . . . . . . . . 625

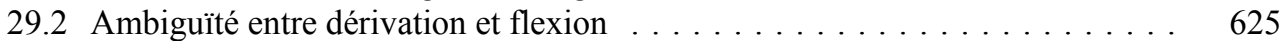

29.2.1 L'alternance suffixale de genre : flexion ou dérivation ? . . . . . 625

29.2.2 Le suffixe évaluatif -ette : de la dérivation à la flexion ? . . . . . 627 
29.2.3 Ambiguïtés intrinsèques . . . . . . . . . . . . . . . . . 628

29.2.3.1 -ant et -é . . . . . . . . . . . . . . . . . . . 628

29.2.3.2 Le suffixe -ment . . . . . . . . . . . . . . . . . . . . . 629

29.2.3.3 Le $-s$ adverbial . . . . . . . . . . . . . . 630

\section{Chapitre 30}

Catégories variables : noms, adjectifs, pronoms et déterminants (AC, CGB, CMN et LS)

30.1 Les catégories nominales : noms, adjectifs et participes (LS). . . . . . . .

30.1.1 Les formes du nom, de l'adjectif et des participes au cours de la période allant du latin au début $\mathrm{du} 12^{\mathrm{e}} \mathrm{s} . \ldots \ldots \ldots \ldots \ldots \ldots$

30.1.1.1 Les catégories nominales de la langue latine transmises au français : cas et nombre $\ldots \ldots \ldots \ldots \ldots \ldots$

30.1.1.2 Les catégories nominales de la langue latine transmises au

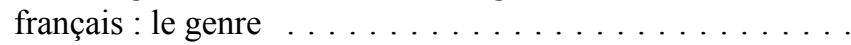

30.1.1.3 Les catégories nominales de la langue latine transmises au français : le degré de comparaison . . . . . . . . . . . . 640

30.1.1.4 Les modifications formelles survenues depuis le latin classique . . . . . . . . . . . . . . . . . . . . 640

a. La déclinaison . . . . . . . . . . . . . . . . . 640

b. Structures synthétiques et analytiques . . . . . . . 641

30.1.2 Les formes du nom, de l'adjectif et des participes au cours de la période de l'ancien français $\left(12^{\mathrm{e}}\right.$ et $\left.13^{\mathrm{e}} \mathrm{s}.\right) \ldots \ldots \ldots \ldots \ldots \ldots .642$

30.1.2.1 Les formes nominales « basiques » de l'ancien français ... 643

30.1.2.2 Le degré de comparaison en ancien français . . . . . . . . . 644

30.1.2.3 La variation des formes nominales et les distinctions diasystématiques . . . . . . . . . . . . . . . 645

a. Le processus de réduction du système casuel : les formes 645

b. D'autres réorganisations formelles . . . . . . . . . . 648

30.1.2.4 Le rôle des fonctions . . . . . . . . . . . . . . . . . . . . 649

a. Présence dominante des formes du cas régime . . . . . 649

b. La variation des formes nominales dépendant de facteurs diasystématiques liés à l'usage (diastratie -

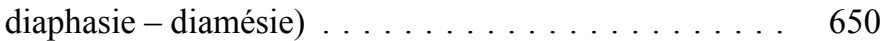

i. La variation diastratique . . . . . . . . . . . 650

ii. La variation diaphasique $\ldots \ldots \ldots \ldots \ldots \ldots 60$

iii. La variation diamésique $\ldots \ldots \ldots \ldots \ldots \ldots 60$

c. La variation des formes nominales dépendant de facteurs linguistiques $\ldots \ldots \ldots \ldots \ldots \ldots 650$

d. La déclinaison bicasuelle était-elle «nécessaire» pour la compréhension de la phrase dans l'ancienne langue ?...................... 651

30.1.3 Les formes et les fonctions nominales au cours de la période du $14^{\mathrm{e}}$

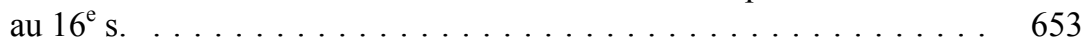
30.1.3.1 L'abandon de la déclinaison casuelle . . . . . . . . . . . 653 
30.1.3.2 Les réorganisations analogiques $\ldots \ldots \ldots \ldots \ldots \ldots 654$

30.1.3.3 L'influence de l'établissement du groupe nominal sur la morphologie .....................

30.1.4 Les formes du nom, de l'adjectif et des participes au cours de la

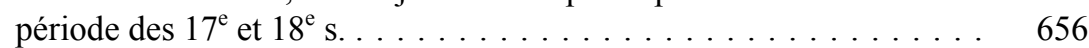

30.1.4.1 Le genre du nom . . . . . . . . . . . . . . 657

30.1.4.2 La formation des mots : préfixes et suffixes . . . . . . . 657

30.1.4.3 La formation des mots caractéristique des Précieuses ... 657

30.1.4.4 Les variations selon l'usage (diaphasie, diamésie, diastratie) . . . . . . . . . . . . . . . . . . 657

a. La diaphasie . . . . . . . . . . . . . . . 657

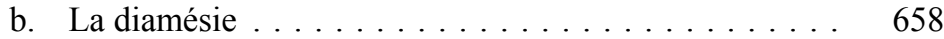

c. La diastratie : le langage des femmes . . . . . . . 658

30.1.5 Les formes du nom, de l'adjectif et des participes du français

moderne, et en particulier du français avancé $\ldots \ldots \ldots \ldots \ldots .660$

30.1.5.1 Le renouvellement du vocabulaire . . . . . . . . . . . . 660

a. La féminisation des titres et fonctions . . . . . . . . 660

b. Le renouvellement du vocabulaire, le langage « des jeunes » ou « français avancé » . . . . . . . . . . 661

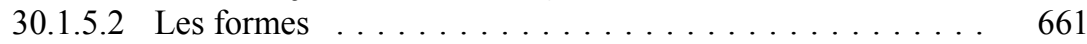

a. Les catégories morphologiques du genre et du nombre ..................... 661

b. Implications typologiques $\ldots \ldots \ldots \ldots \ldots 662$

30.1.5.3 Analyse diasystémique de la variation morphologique en français moderne . . . . . . . . . . . . . . . . 663

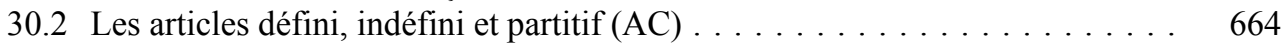

30.2.1 Le paradigme des articles : quelques éléments de chronologie . . . . 664

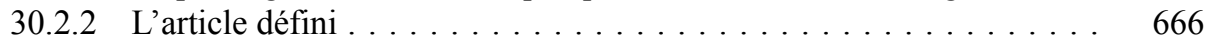

30.2 .2 .1 Origine latine $\ldots \ldots \ldots \ldots \ldots \ldots \ldots \ldots \ldots \ldots 66$

30.2.2.2 Les formes fléchies de l'article défini . . . . . . . . . . 666

30.2.2.3 Les variantes . . . . . . . . . . . . . . . . . . . . 667

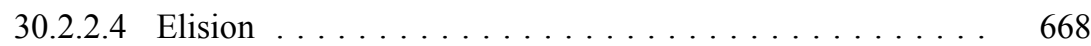

30.2.2.5 Enclise . . . . . . . . . . . . . . . . 668

30.2.2.6 La mise en place du paradigme moderne des articles définis . . . . . . . . . . . . . . . . . 670

30.2.3 L'article indéfini issu du numéral de l'unité unus . . . . . . . . . 671

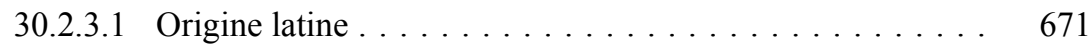

30.2.3.2 Les formes fléchies de l'article indéfini $\ldots \ldots \ldots \ldots \ldots 671$

30.2.3.3 Les variantes . . . . . . . . . . . . . . . . . 672

30.2.3.4 Elision . . . . . . . . . . . . . . . . . . . 672

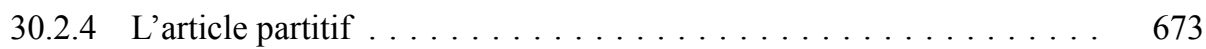

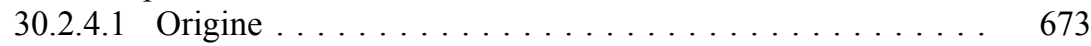

30.2.4.2 Les formes de l'article partitif . . . . . . . . . . . . 673

30.2.4.3 Les variantes . . . . . . . . . . . . . . . . . . . . 673

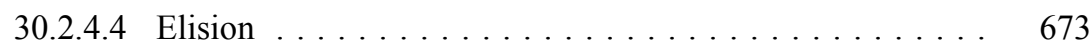

30.3 Les pronoms personnels, et $\mathrm{EN}, \mathrm{Y}$ et $\mathrm{ON}(\mathrm{CMN}) \ldots \ldots \ldots \ldots \ldots \ldots 674$

30.3 .1 Introduction $\ldots \ldots \ldots \ldots \ldots \ldots \ldots \ldots \ldots \ldots \ldots \ldots \ldots$ 
30.3.2 Le système des pronoms personnels du $9^{\mathrm{e}}$ au $15^{\mathrm{e}} \mathrm{s}$.

30.3.2.1 Pronoms personnels sujets du $9^{\mathrm{e}}$ au $15^{\mathrm{e}} \mathrm{s}$. : formes toniques et atones, enclise et proclise des CS atones . . . . . . . . .

a. Forme du pronom personnel sujet : tonique ? atone ? indifférencié . . . . . . . . . . . . . . . . 677

b. Formes des pronoms personnels sujets . . . . . . . . 679

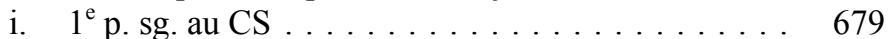

ii. $2^{\mathrm{e}}$ p. sg. au CS ................... 680

iii. $3^{\mathrm{e}}$ p. sg. au CS, masc., fém., neutre ......... 681

iv. $1^{\mathrm{e}}$ et $2^{\mathrm{e}}$ p. pl. au CS $\left(4^{\mathrm{e}}\right.$ et $5^{\mathrm{e}}$ p. $) \ldots \ldots \ldots \ldots 682$

v. $3^{\mathrm{e}}$ p. pl. au CS $\left(6^{\mathrm{e}}\right.$ p. $)$, masc. et fém. . . . . . . 682

vi. Le pronom indéfini sujet $\mathrm{ON}$ : vers un pronom «omnipersonnel $» \ldots \ldots \ldots \ldots \ldots \ldots$

30.3.2.2 Pronoms personnels régimes du $9^{\mathrm{e}}$ au $15^{\mathrm{e}} \mathrm{s}$. : formes toniques et atones, enclise et proclise des CR atones . . . . .

a. Enclise et proclise des pronoms personnels régimes

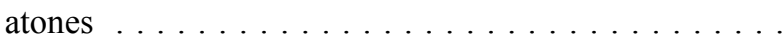

b. Formes des pronoms régimes . . . . . . . . . 685

i. $\quad 1^{\mathrm{e}}$ p. sg., $2^{\mathrm{e}}$ p. sg. et réfléchi au CR ........ 685

ii. $3^{\mathrm{e}}$ p. sg. au CR masc., fém. et neutre ........ 686

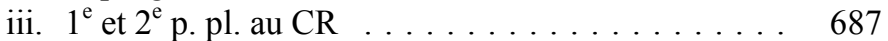

iv. $3^{\mathrm{e}}$ p. pl. au CR masc. et fém. . . . . . . . . . . 687

30.3.3 Le système des pronoms personnels du $16^{\mathrm{e}}$ au $21^{\mathrm{e}} \mathrm{s} . \ldots \ldots \ldots \ldots 7$

30.3.3.1 Changements dans les formes . . . . . . . . . . 688

30.3.3.2 La cliticisation du pronom sujet et l'emploi des formes de CR toniques : de il meïsmes à lui-même . . . . . . 688

30.3.3.3 Développement du pronom indéfini sujet $\mathrm{ON}$ en un pronom personnel P4 : formes et valeur . . . . . . . . 689

30.4 Les démonstratifs : déterminants et pronoms (CGB) . . . . . . . . . . . . . 692

30.4.1 Le système des démonstratifs aux origines $\left(9^{\mathrm{e}}\right.$-fin $\left.12^{\mathrm{e}} \mathrm{s}.\right) \ldots \ldots \ldots 2$

30.4.2 La spécialisation catégorielle des démonstratifs $\left(13^{\mathrm{e}}-17^{\mathrm{e}} \mathrm{s}.\right) \ldots \ldots . . .694$

30.4.3 L'apparition et le développement des formes suffixées

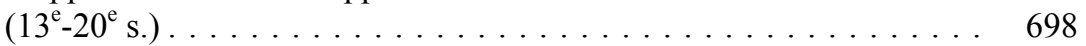

30.4.4 Le sous-système des formes neutres et l'explosion de ça

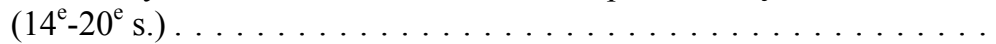

30.4.5 Le système du français standard et ses variations . . . . . . . . . . . . 701

30.5 Les possessifs : déterminants, adjectifs et pronoms $(\mathrm{CMN}) \ldots \ldots \ldots 2$

30.5.1 Un système complexe de sous-paradigmes : les étapes d'une

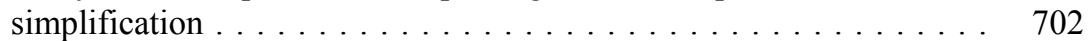

30.5.1.1 Un système à l'origine très diversifié . . . . . . . . . . . 702

30.5.1.2 Les deux paradigmes de possessifs des origines au français

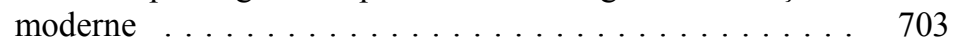

30.5.1.3 Les effets de l'analogie . . . . . . . . . . . . . . . . . 706

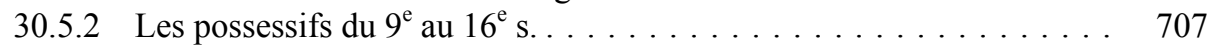

30.5.2.1 Le paradigme des formes de possessifs atones :

déterminants .................... 707

a. $\operatorname{Du} 9^{\mathrm{e}}$ au $13^{\mathrm{e}}$ s. : une grande variété de formes . . . . . 707 
b. Formes dialectales . . . . . . . . . . . . . 708

i. Anglo-normand et normand : $11^{\mathrm{e}}-14^{\mathrm{e}} \mathrm{s} . \ldots \ldots .709$

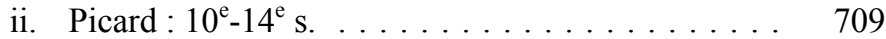

iii. Wallon .................... 709

c. Fin $13^{\mathrm{e}}-14^{\mathrm{e}}-15^{\mathrm{e}} \mathrm{s}$ : phases de changement, mise en place du système moderne . . . . . . . . . . . . . 709

30.5.2.2 Le paradigme des formes toniques de possessifs : adjectif, pronom et nom . . . . . . . . . . . . . . . . . . 711

a. Trois fonctions pour une seule forme $\ldots \ldots \ldots \ldots .711$

b. Les paradigmes « primitifs » en Très Ancien Français .................... 711

c. La première vague d'analogies $\left(11^{\mathrm{e}}-12^{\mathrm{e}} \mathrm{s}.\right) \ldots \ldots \ldots 712$

d. Deux nouvelles vagues d'analogies : masculin mien $\rightarrow$ tien, sien (seconde moitié du $12^{\mathrm{e}} \mathrm{s}$.) ; féminin moie $\rightarrow$ toie, soie (début-fin $12^{\mathrm{e}} \mathrm{s}$.) … . . . . . . . . 713

e. Formes dialectales ................ 713

i. Anglo-normand et normand : analogies . . . . . . 713

ii. Picard : analogies ............... 714

f. $14^{\mathrm{e}}-15^{\mathrm{e}} \mathrm{s}$ : : quatrième et dernière vague d'analogie : mienne, tienne, sienne $\left(14^{\mathrm{e}} \mathrm{s}.\right)$; distinction paradigmisée entre déterminants et pronoms . . . . . 714

30.5.3 Les possessifs du $17^{\mathrm{e}} \mathrm{s}$. au français moderne . . . . . . . . . . 714

30.5.4 Conclusion sur l'évolution des paradigmes de possessifs . . . . . . 715

30.6 Les indéfinis : déterminants, adjectifs et pronoms $(\mathrm{CMN}) \ldots \ldots \ldots \ldots \ldots$

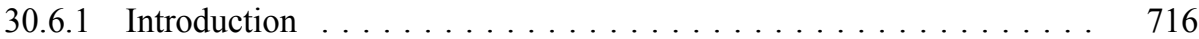

30.6.2 Pronoms et déterminants indéfinis quantifieurs à polarité négative ou à valeur indéterminée . . . . . . . . . . . . . . . . . . . 717

30.6.3 Pronoms et déterminants indéfinis quantifieurs à valeur

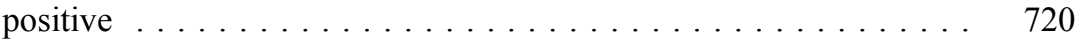

30.6.4 Pronoms et déterminants indéfinis identifieurs . . . . . . . . . . 724

30.7 Les numéraux : déterminants et pronoms $(\mathrm{CMN}) \ldots \ldots \ldots \ldots \ldots \ldots \ldots$

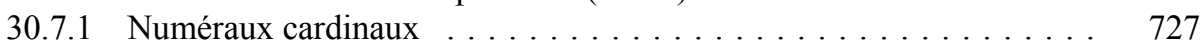

30.7.1.1 Un, deux, trois . . . . . . . . . . . . . . . . 727

30.7.1.2 De dix à vingt . . . . . . . . . . . . . . . . . . . . . 728

30.7.1.3 De vingt et un à mille . . . . . . . . . . . . . . . . . . . . 729

30.7.2 Numéraux ordinaux . . . . . . . . . . . . . . . . . . . 730

30.8 Les relatifs, interrogatifs, exclamatifs : déterminants, pronoms et adverbes

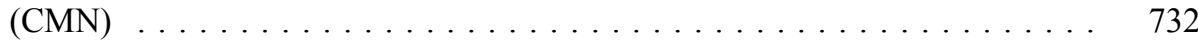

30.8.1 Paradigmes pronominaux : une structure commune . . . . . . . 732

30.8.2 Les relatifs, interrogatifs et exclamatifs : formes en QU- . . . . . . 733

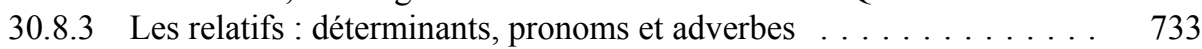

30.8.3.1 Les formes de sujet . . . . . . . . . . . . . . 734

a. La forme de sujet qui (antécédent animé) _...... 734

b. La forme qui de sujet indéterminé (ou à antécédent propositionnel . . . . . . . . . . . . . . . . 735

c. La forme que de sujet neutre, à antécédent indéterminé ou propositionnel . . . . . . . . . . . . . 736 
30.8.3.2 Les formes du complément d'objet direct que et cui, quoi ....................... 736

a. La forme atone que .............. 736

b. La forme régime tonique : cui (antécédent animé) $\left(9^{\mathrm{e}}-15^{\mathrm{e}} \mathrm{s}\right.$.) $>$ qui (antécédent animé ou inanimé) et

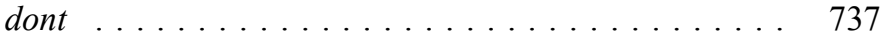

c. La forme de régime tonique (antécédent inanimé ou propositionnel) coi / kei / quei / quoi . . . . . . . . . . 738

30.8.3.3 Les formes en -quel . . . . . . . . . . . . . . . . . . . . . 739

30.8.3.4 Les formes en quant, quanque . . . . . . . . . . . . 740

30.8.3.5 Les adverbes dont, où, ont $(<$ lat. unde $)\left(12^{\mathrm{e}}-14^{\mathrm{e}} \mathrm{s}.\right) \ldots \ldots \quad 740$

30.8.3.6 Les formes composées en « relatif $+q u e »$ à valeur indéterminée . . . . . . . . . . . . . . . . . . . 741

30.8.4 Les morphèmes interrogatifs : pronoms, déterminants, adverbes ... 741

30.8.4.1 Les morphèmes interrogatifs de l'interrogation partielle . . . . . . . . . . . . . . . . 741

30.8.4.2 Un marqueur tardif de l'interrogation : la locution est ce que ..................... 742

30.8.5 Exclamatifs : existe-t-il un paradigme des exclamatifs ? . . . . . 743

\section{Chapitre 31}

Catégories variables : le verbe $(\mathbf{S B T}) \ldots \ldots \ldots \ldots \ldots \ldots \ldots \ldots \ldots \ldots \ldots$

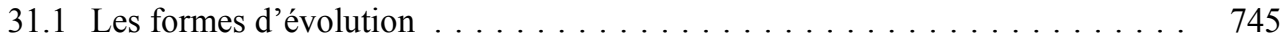

31.2 Méthode d'analyse . . . . . . . . . . . . . . . . . . . . . 746

31.2.1 La notion de tiroir verbal . . . . . . . . . . . . . . . . 746

31.2.2 Radical et / ou base, variantes . . . . . . . . . . . . . . . 746

31.2.3 Désinences, marques ou morphèmes flexionnels . . . . . . . . . 747

31.2.4 Groupes verbaux et verbes « anomaux » . . . . . . . . . . . . . . 747

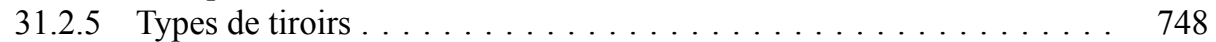

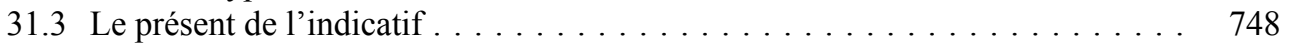

31.3.1 Ancien et moyen français . . . . . . . . . . . . . . . . 748

31.3.1.1 Structure accentuelle . . . . . . . . . . . . . . 748

31.3.1.2 Opposition entre les verbes en -er / -ier et les autres verbes . . . . . . . . . . . . . . . . . . . . 749

31.3.1.3 Les marques de personne $\ldots \ldots \ldots \ldots \ldots \ldots \ldots \ldots \quad 750$

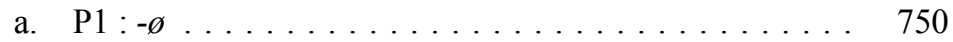

i. Extension de la marque $-e \ldots \ldots \ldots \ldots \ldots 750$

ii. Extension de $-s$ pour les autres verbes $\ldots \ldots \ldots 750$

b. P2: $-s$ ou $-z \ldots \ldots \ldots \ldots \ldots \ldots \ldots \ldots \ldots \ldots \ldots$

c. P3:-t ou $-\varnothing \ldots \ldots \ldots \ldots \ldots \ldots \ldots \ldots \ldots \ldots$

d. P4:-ons; variantes : -omes et -mes . . . . . . 752

e. P5:-ez/-iez;-tes ... . . . . . . . . . 752

f. P6:-ent .................... 753

31.3.1.4 Les bases . . . . . . . . . . . . . . . . . . . . 754

a. Verbes à une seule base (type 1) . . . . . . . . 754 
b. Verbes à deux bases . . . . . . . . . . . . . . . 754

i. Type $2 \mathrm{a}$ : opposition $\mathrm{P} 1$ (B3) / reste du paradigme

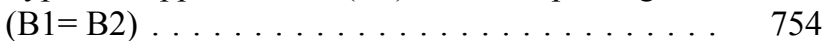

ii. Type $2 \mathrm{~b}$ : opposition $\mathrm{B} 2$ (P1, P2, P3, P6) et B1

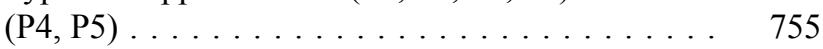

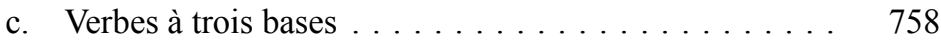

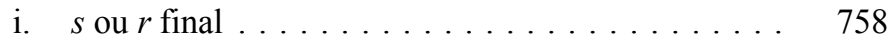

ii. $/ K / \ldots \ldots \ldots \ldots \ldots \ldots \ldots \ldots \ldots$

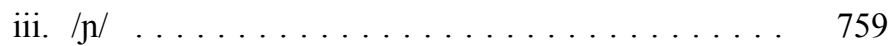

iv. $/ \mathrm{dj} / \mathrm{ou} / \mathrm{jj} / \ldots \ldots \ldots \ldots \ldots \ldots \ldots$. . . . . . . . . . . . . . . . . . . . . . . 759

d. Verbes anomaux ... . . . . . . . . . . . . 760

i. Verbes entièrement forts, c'est-à-dire accentués sur le radical à toutes les personnes : estre, dire, faire . 760

ii. avoir ai, as, a, avons, avez, ont . . . . . . . 760

iii. aler voi / vois / vais, vas, va, alons, alez, ont . . . 761

31.3.2 Evolution jusqu'au français moderne . . . . . . . . . . . . 761

31.3.2.1 La structure accentuelle . . . . . . . . . . . . . 761

31.3.2.2 L'opposition entre les verbes en -er et les autres verbes . . . 761

31.3.2.3 Les marques de personne . . . . . . . . . . . . . . 762

31.3.2.4 Les bases . . . . . . . . . . . . . . . 764

a. Réduction du nombre de bases : aimer, pleurer . . . . 764

b. Evolution de la nature de l'alternance : lever / grever, voir / croire . . . . . . . . . . . . . . . 764

c. Maintien des alternances : pouvoir, vouloir ...... 765

d. Tentative de réduction des formes en -ète . . . . . . . 765

e. Hésitations entre conjugaisons inchoatives et non

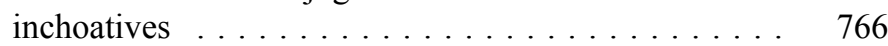

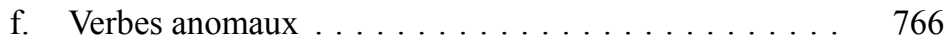

31.4 Le présent du subjonctif . . . . . . . . . . . . . . . . . 767

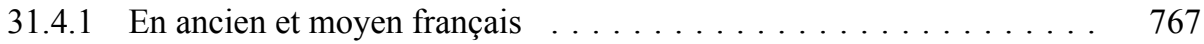

31.4.1.1 La structure accentuelle . . . . . . . . . . . . . . 767

31.4.1.2 Opposition des verbes en -er / -ier et des autres verbes . . . 767

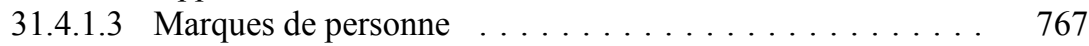

31.4.1.4 Bases . . . . . . . . . . . . . . . . . . . 770

a. Verbes à une seule base aux présents de l'indicatif et du subjonctif $(\mathrm{B} 1=\mathrm{B} 2) \ldots \ldots \ldots \ldots$

b. Verbes à deux bases au présent de l'indicatif . . . . . . 771

i. Verbes à alternance $\mathrm{B} 1 / \mathrm{B} 2$ au présent de

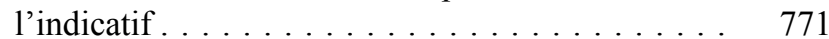

ii. $\mathrm{B} 3 / \mathrm{B} 1=\mathrm{B} 2 \ldots \ldots \ldots \ldots \ldots \ldots$

c. Les verbes à trois bases .............. 771

d. Les verbes anomaux . . . . . . . . . . . . . . . . . 772

31.4.2 Evolution jusqu'en français moderne . . . . . . . . . . . . . . . 773

31.4.2.1 Structure accentuelle : pas de changement . . . . . . . . . 773

31.4.2.2 L'opposition entre les verbes en -er et les autres verbes disparaît ....................... 773 
31.4.2.3 Marques de personne . . . . . . . . . . . . . . . . 774

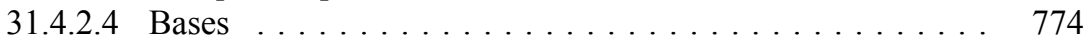

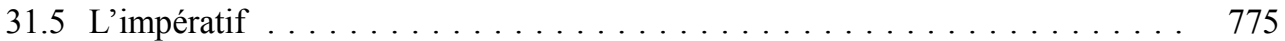

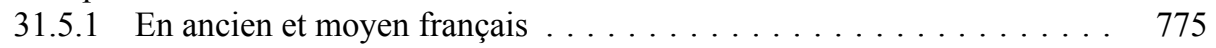

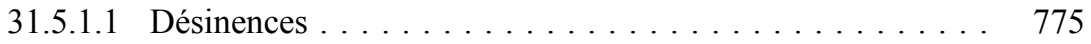

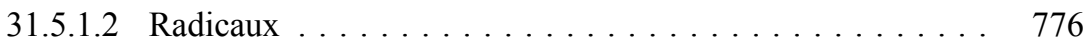

31.5.2 Evolution jusqu'au français moderne . . . . . . . . . . . . . 776

31.5.2.1 Désinences . . . . . . . . . . . . . . . . . . . . 776

31.5.2.2 Radicaux . . . . . . . . . . . . . . . . . . . . . . . . . 777

31.6 L'imparfait de l'indicatif . . . . . . . . . . . . . . . . . . . . . 777

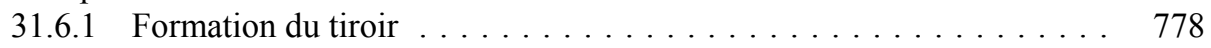

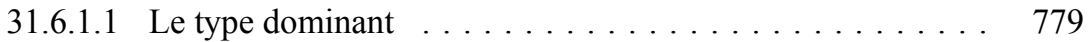

a. $\mathrm{P} 1, \mathrm{P} 2, \mathrm{P} 3, \mathrm{P} 6 \ldots \ldots \ldots \ldots \ldots \ldots \ldots$

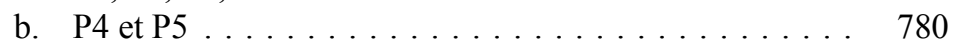

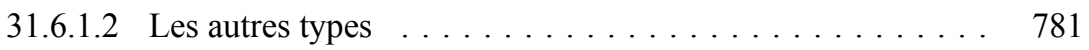

a. Verbes en $-e r /-i e r \ldots \ldots \ldots \ldots \ldots \ldots 1$

b. Verbe estre . . . . . . . . . . . . . . . . 782

31.6.2 Evolution du tiroir en moyen français . . . . . . . . . . . . . . . 783

31.6.2.1 Changements de base . . . . . . . . . . . . 783

31.6.2.2 Généralisation du type dominant et disparition des types

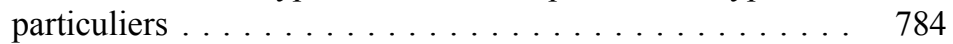

31.6.2.3 Hésitations sur les marques . . . . . . . . . . . . . . . 784

a. La marque de tiroir en P1, P2, P3, P6 . . . . . . 784

b. La disparition de $e$ en $\mathrm{P} 1, \mathrm{P} 2$ et $\mathrm{P} 6 \ldots \ldots \ldots \ldots$

c. Les marques de personne . . . . . . . . . . . 787

i. $\quad \mathrm{P} 1, \mathrm{P} 2 \ldots \ldots \ldots \ldots \ldots \ldots \ldots \ldots \ldots$

ii. $\quad \mathrm{P} 3 \ldots \ldots \ldots \ldots \ldots \ldots \ldots \ldots \ldots$

iii. $\mathrm{P} 4, \mathrm{P} 5 \ldots \ldots \ldots \ldots \ldots \ldots \ldots \ldots$

31.6.3 Evolution du tiroir en français classique et moderne . . . . . . . . 788

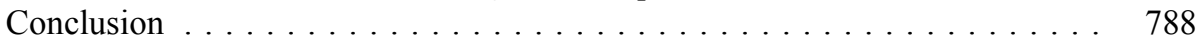

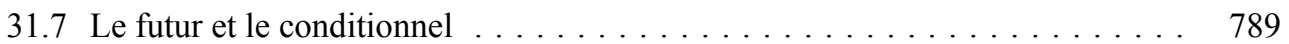

31.7.1 La formation du tiroir . . . . . . . . . . . . . . . . . 789

31.7.2 La situation des deux tiroirs en ancien français . . . . . . . . . . . 790

31.7.2.1 Les marques de tiroir et de personne en ancien français. . . . 790

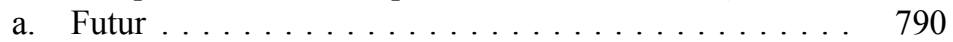

b. Conditionnel . . . . . . . . . . . . . . . . . 792

31.7.2.2 Les radicaux de futur et de conditionnel . . . . . . . . . 793

a. Base $\mathrm{B} 1+e+R+$ désinences ........... 793

i. Verbes en -er / -ier, à l'exception des verbes dont le radical se termine par une nasale (doner, mener) ou $r$ (durer, plorer) (voir ci-dessous) . . . . . . . . . 793

ii. Verbes autres qu'en -er / -ier . . . . . . . . . . 794

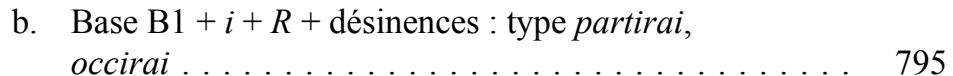

c. Base $\mathrm{B} 1+\varnothing+R+$ désinences $\ldots \ldots \ldots \ldots \ldots \ldots 795$

i. Verbes en - er $/$-ier . . . . . . . . . . . . . . . 795

ii. Verbes autres qu'en $-\mathrm{er} / \mathrm{ier} \ldots \ldots \ldots \ldots$. . . 796 
d. Base atone $\mathrm{B} 1+$ consonne épenthétique $+R+$ désinences . . . . . . . . . . . . . . . . . . 797

i. Radical terminé par une liquide $: l+r>-l d r->$ $-u d r-\ldots \ldots \ldots \ldots \ldots \ldots$

ii. Radical terminé par une nasale : apparition d'une consonne épenthétique . . . . . . . . . . . . . 798

e. Base propre au futur $+R+$ désinences $\ldots \ldots \ldots \ldots .798$

i. Verbes oïr, pooir, veoir : base élargie en $-r$ - . . . . 798

ii. Verbe aler ................... 798

iii. Verbes faire et laissier . . . . . . . . . . . . . . . . . . . 799

iv. Verbes avoir et savoir . . . . . . . . . . . . . . 799

v. Verbe estre . . . . . . . . . . . . . . . . . . . . . 799

31.7.3 Evolution à partir du moyen français . . . . . . . . . . . . . . . 800

31.7.3.1 Les marques de tiroir et de personne . . . . . . . . . . . . 800

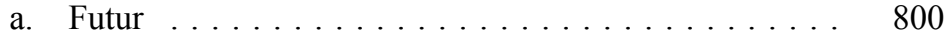

i. $\quad \mathrm{P} 1-a i$ et les variantes $-\dot{e},-a y \ldots \ldots \ldots$. . . . 801

ii. P5 : la variante $-e ́ s \ldots \ldots \ldots$. . . . . . . 801

iii. P4 / P6 -on : effacement de la consonne finale muette . . . . . . . . . . . . . . . . . 801

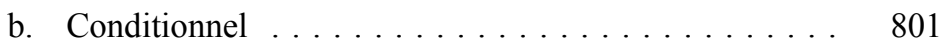

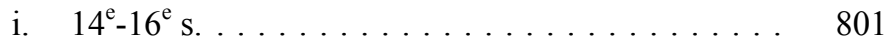

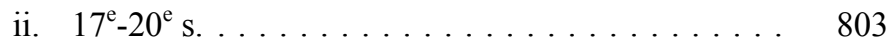

31.7.3.2 Les radicaux de futur et de conditionnel . . . . . . . . . . . 804

a. Effacement de $e$ caduc après voyelle pour les futurs des verbes en $-e r \ldots \ldots \ldots$. . . . . . . . . . . . . 804

b. Abandon des formes syncopées et des formes avec

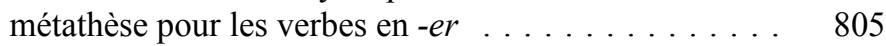

i. Base terminée par nasale : le cas de donner et mener ................... 805

ii. Base terminée par la consonne $r$ : demeurer, durer, jurer, pleurer ............... 805

iii. Les formes avec métathèse : deliverra pour delivrera ................... 806

c. Remplacement de $e$ caduc par $i$ pour les verbes du type ouvrir ou souffrir . . . . . . . . . . . . . . . . 806

d. Disparition des radicaux en - $r r$ - des verbes en -ir-au profit de formes élargies . . . . . . . . . . . . . . . . . 806

e. Le $e$ svarabhaktique . . . . . . . . . . . . . 807

f. Maintien de la base de futur ou réalignement sur une autre base . . . . . . . . . . . . . . . . . 808

i. Généralisation de la base forte du présent . . . . 808

ii. Changement de thème mais maintien d'une base élargie au futur . . . . . . . . . . . . . . . . 808

iii. Généralisation du radical palatalisé $+e / i \ldots \ldots 808$

iv. Certains verbes conservent leur base spécifique de futur : pourra, verra ...................... 809 


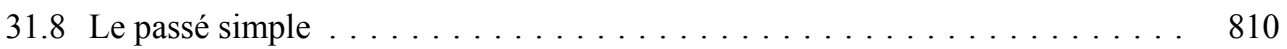

31.8.1 Formation du tiroir du latin à l'ancien français . . . . . . . . . . . . . . 810

31.8.1.1 Les passés simples faibles et « hybrides » . . . . . . . . . 811

a. Les différents types ................ 811

i. Type 1 - voyelle thématique /a/ et ses variantes $/ \mathrm{e} /$ et $/(\mathrm{j}) \varepsilon / \ldots \ldots \ldots \ldots$. . . . . . . . . . . 812

ii. Type 2 - voyelle /i/ : verbes en -ir (dormir) et verbes issus des parfaits latins en -dedi . . . . . 812

iii. Type 2 bis ancien - voyelle /i/ /ie/ : vendre, batre, naistre, perdre, repondre, veintre, vivre vendi, vendis, vendie $(t)$, vendimes, vendistes, vendierent

iv. Type 3 - hybride - voyelle/y/ : corui, corus, coru(t), corumes, corustes, corurent . . . . . . . . . . . . 813

v. Verbe estre . . . . . . . . . . . . . . . 813

b. Les désinences .................. 813

i. $\quad P 1 \ldots \ldots \ldots \ldots \ldots \ldots \ldots$

ii. $\quad \mathrm{P} 2 \ldots \ldots \ldots \ldots \ldots \ldots \ldots \ldots$

iii. $\mathrm{P} 3 \ldots \ldots \ldots \ldots \ldots \ldots \ldots \ldots$

iv. $\mathrm{P} 4:-$ mes $_{1} \ldots \ldots \ldots \ldots \ldots \ldots \ldots \ldots$

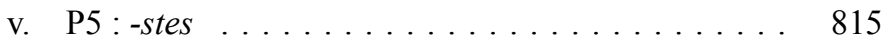

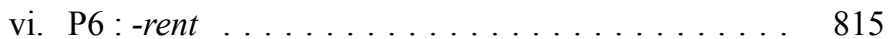

31.8.1.2 Les passés simples « forts » ou mixtes . . . . . . . . . . . 815

a. Formation des différents types . . . . . . . . 815

i. $\quad$ Type en $-i$ simple : veoir, passé simple en - $i$ - / -ë̈- 816

ii. Type en $-i+$ nasale : venir, tenir et leurs dérivés . . 816

iii. Type sigmatique $:-i s-/-e(s) i-\ldots \ldots \ldots \ldots$

iv. Type en $-u$ avec alternance $-o-/-e \ddot{u}-\ldots \ldots . \ldots 818$

v. Type en $-u$ avec alternance $-u-/-e \ddot{u}-\ldots \ldots . \ldots 819$

b. Les désinences en ancien français . . . . . . . . . . . . . 819

31.8.2 Evolution de l'ancien français au français moderne . . . . . . . . . . . . . 820

31.8.2.1 Les passés simples faibles et « hybrides » . . . . . . . . . . . 821

a. Changement de base ou de modèle de conjugaison . . . 821

b. Evolution des désinences à partir du moyen français .................... 821

31.8.2.2 Les passés simples forts . . . . . . . . . . . . . . . . . 824

a. Changement de base ou de conjugaison . . . . . . . . 824

b. Disparition de l'alternance entre B5 et B6 . . . . . 825

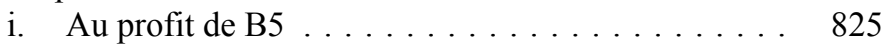

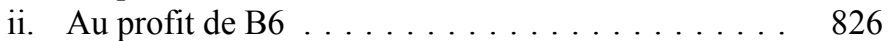

c. Evolution des désinences à partir du moyen français . . 827

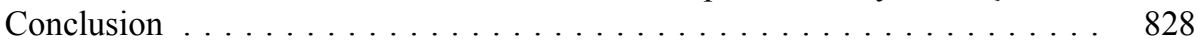

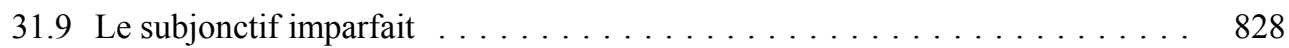

31.9.1 Formation en ancien français et moyen français . . . . . . . . . . . . . . . . 829

31.9.1.1 Les différents types . . . . . . . . . . . . . . . . . 829

a. Formation des subjonctifs imparfaits sur B1 . . . . . 829

i. Voyelle $a$ : amasse, -sses, -sse, amissons / -ssions, amissez / -iez, amassent . . . . . . . . . . 
ii. Voyelle $i$ : mentisse, mentisses, mentist, mentissons / -ions, mentissez / -iez, mentissent . . . . . . . . . .

iii. Voyelle $u$ : fusse, fusses, fust, fussons / -iens / -ions, fussez / -iez, fussent . . . . . . . . . 830

b. Formation des subjonctifs imparfaits des verbes à passés simples forts (sur B6) . . . . . . . . . . . 830

i. Voyelle $i$ : venisse, venisses, venist, venissiens, venissiez, venissent . . . . . . . . . . .

. Voyelle $u$ : eüsse, eüsses, eüst, eüssons / -iens / -ions, eüssez / -iez, eüssent . . . . . . . . . . . . . . . . . . . . . 831

31.9.1.2 Les désinences . . . . . . . . . . . . . . . . . . . 832

31.9.2 Evolution du subjonctif imparfait du moyen français au français moderne . . . . . . . . . . . . . . . . . . . . . . . . 833

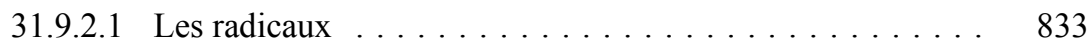

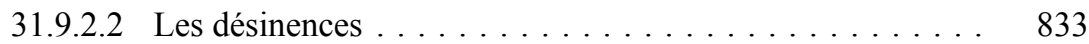

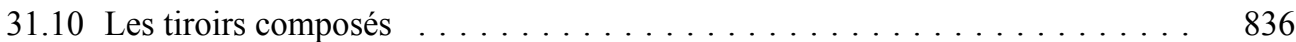

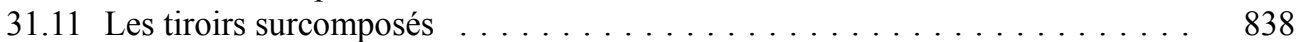

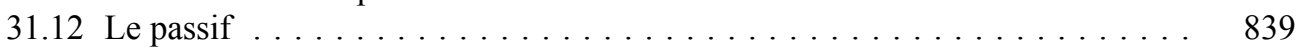

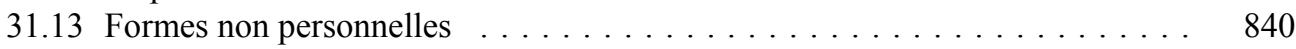

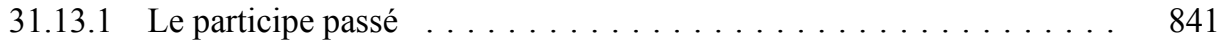

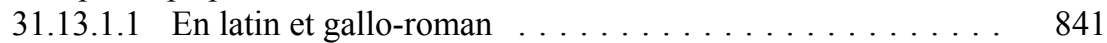

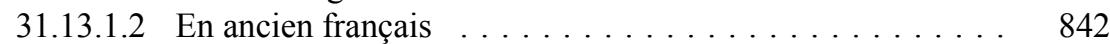

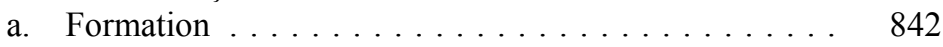

b. Les morphèmes de tiroir . . . . . . . . . . . . . . 843

31.13.1.3 Evolution de l'ancien français au français moderne . . . . . . 845

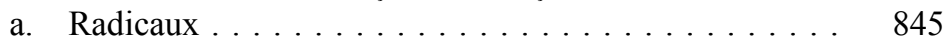

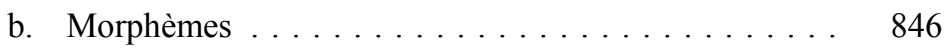

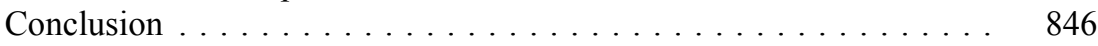

31.13 .2 L'infinitif . . . . . . . . . . . . . . . . . . . . 847

31.13.2.1 Un système transmis par le latin vulgaire . . . . . . . . . . 847

31.13.2.2 Les infinitifs en ancien français . . . . . . . . . . . . . . . . 847

a. Les morphèmes de tiroir . . . . . . . . . . . . . . . . 848

i. Types A, B et C : types faibles . . . . . . . . 848

ii. Type D : type fort (l'accent porte sur la base) . . . 849

b. Alternances .................... 849

i. Entre les types C et D . . . . . . . . . . . . . . . . . 849

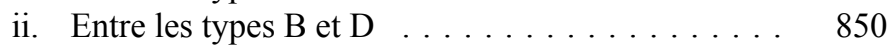

iii. Entre les types A et B . . . . . . . . . . . 850

31.13.2.3 Evolution jusqu'en français moderne . . . . . . . . . . 850

a. Morphèmes . . . . . . . . . . . . . . . . . 850

b. Alignements et simplifications .......... 851

i. Extension de la base forte : aimer, nier ...... 851

ii. Changement d'infinitif : courir et quérir . . . . . 851

iii. Elimination des alternances . . . . . . . . . 851

Conclusion ........................ 852 
31.13.3 Le participe présent et le gérondif $\ldots \ldots \ldots \ldots \ldots \ldots \ldots . \quad 852$

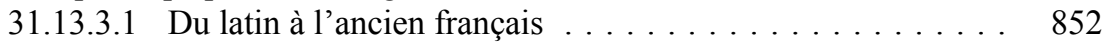

a. Les formes variables $\ldots \ldots \ldots \ldots \ldots \ldots \ldots$. . . . 852

b. Les formes invariables . . . . . . . . . . . . 853

31.13.3.2 De l'ancien français au français moderne . . . . . . . 854

a. Les formes variables . . . . . . . . . . . . 854

b. Extension de l'invariabilité à l'ensemble des formes verbales en -ant . . . . . . . . . . . . . . . . 854

\section{Chapitre 32}

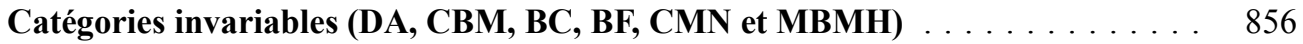

32.1 Prépositions et locutions prépositives (BF) $\ldots \ldots \ldots \ldots \ldots \ldots \ldots \ldots$

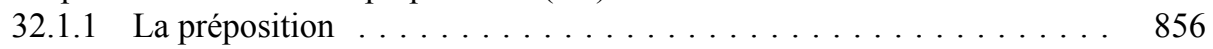

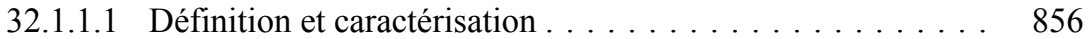

32.1.1.2 Propriétés atypiques et grammaticalisation . . . . . . . . . 857

32.1.1.3 Une catégorie peu homogène . . . . . . . . . . . . . . . . 859

32.1.1.4 Les locutions prépositionnelles : une identification

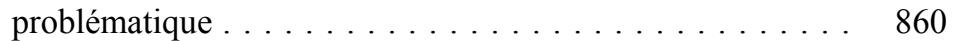

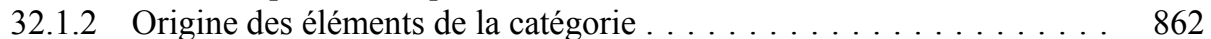

32.1.2.1 Disparition des cas . . . . . . . . . . . . . . 863

32.1.2.2 Apparition des prépositions fonctionnelles en français ... 863

32.1.2.3 Les locutions prépositionnelles, du latin au français . . . . . 864

32.1.2.4 Une évolution typologique globale . . . . . . . . . . . 865

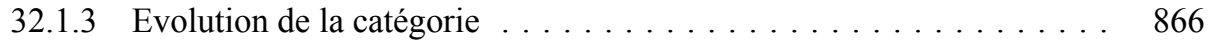

32.1.3.1 Evolutions majeures au cours de la diachronie du

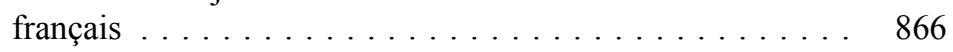

32.1.3.2 Les prépositions fonctionnelles . . . . . . . . . . . 867

a. Ancien français . . . . . . . . . . . . . . . . 867

b. Moyen français . . . . . . . . . . . . . . . . . . 869

c. Français préclassique et classique . . . . . . . . . . 869

d. Français moderne . . . . . . . . . . . . . 870

32.1.3.3 Les prépositions lexicales . . . . . . . . . . . 871

a. Ancien français : héritage latin et roman, premières créations françaises . . . . . . . . . . . . . . 872

b. Moyen français . . . . . . . . . . . . . . 875

c. Français préclassique et classique . . . . . . . . . . 876

d. Français moderne . . . . . . . . . . . . . . . . 877

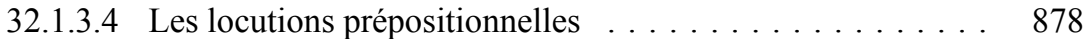

a. Une progression continue . . . . . . . . . . 878

b. Ancien français . . . . . . . . . . . . . . . . 879

c. Moyen français . . . . . . . . . . . . . . . 880

d. Français préclassique et classique . . . . . . . . . 882

e. Français moderne . . . . . . . . . . . . . . . . 884

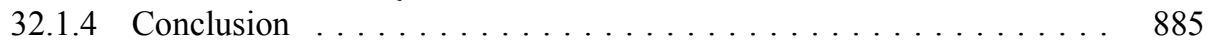


32.2 Préverbes séparables et particules verbales $\left(9^{\mathrm{e}}-16^{\mathrm{e}} \mathrm{s}.\right)$ : deux catégories (presque) disparues ? $(\mathrm{CMN}) \ldots \ldots \ldots \ldots \ldots$. . . . . . . . . . . . . 886

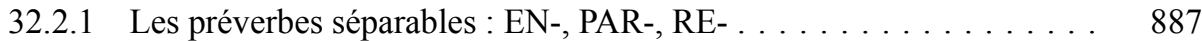

32.2.1.1 Une sous-catégorie de préfixes verbaux : les préverbes séparables en ancien français . . . . . . . . . . . 887

32.2.1.2 Traits caractéristiques des préverbes séparables . . . . . . . 888

a. Le verbe est auxilié par un auxiliaire ou un modal . . . . 888

b. Le verbe a un complément pronom personnel ou

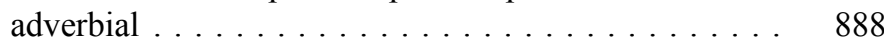

c. EN- postposé au verbe . . . . . . . . . . . . . 889

d. Le préverbe marque l'aspect . . . . . . . . . . . . . . . . . . 889

e. Suite de préverbes . . . . . . . . . . . . . . . 889

32.2.1.3 Le préverbe EN- . . . . . . . . . . . . . . . . . . 889

32.2.1.4 Le préverbe PAR- . . . . . . . . . . . . . . . . . . . . . 890

32.2.1.5 Le préverbe séparable RE- . . . . . . . . . . . . . . 891

32.2.1.6 Des préverbes séparables en français moderne ? . . . . . . . 892

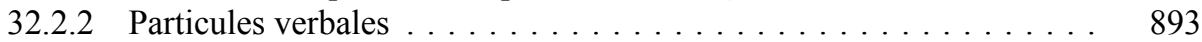

32.2.2.1 Une catégorie syntaxiquement et sémantiquement spécifiée 893

32.2.2.2 Origine et liste des particules verbales en ancien français . . . . . . . . . . . . . . . . . . . 893

32.2.2.3 Traits caractéristiques des particules verbales . . . . . . 895

32.2.2.4 Une catégorie en déclin . . . . . . . . . . . . . . . . . 896

32.2 .3 Conclusion . . . . . . . . . . . . . . . . . . . . 897

32.3 Conjonctions de subordination et locutions conjonctives (BC) . . . . . . . . 897

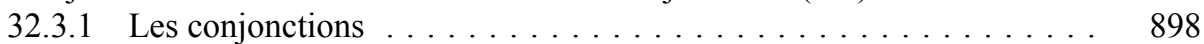

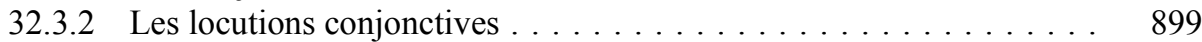

32.3.2.1 Locutions formées avec que . . . . . . . . . . . . . . . . 900

a. Les types de formation . . . . . . . . . . . . . . 900

b. La variation que / ce que . . . . . . . . . . . . . 900

c. Le système latin . . . . . . . . . . . . . . . . . . 901

d. L'ancien français .................. 902

32.3.2.2 L'évolution dans les autres sous-catégories de locutions . . 905

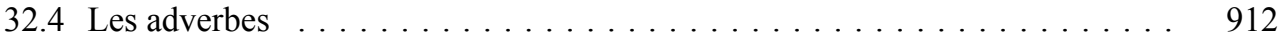

32.4.1 Adverbes et locutions adverbiales : une catégorie en fusion

$(\mathrm{CMN}) \ldots \ldots \ldots \ldots 12$

32.4.1.1 Définition de la catégorie . . . . . . . . . . . . . . . . . 912

32.4.1.2 Origines diverses . . . . . . . . . . . . . . . . . . 913

32.4.1.3 Le $-s$ final adverbial . . . . . . . . . . . . . . . 914

32.4.1.4 Sous-catégories sémantiques des adverbes et locutions . . . 915

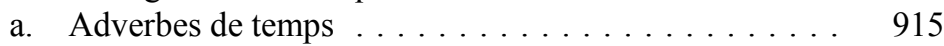

b. Adverbes de lieu . . . . . . . . . . . . . . . . 916

c. Adverbes de manière . . . . . . . . . . . . . . . . 917

d. Adverbes de degré : quantifieurs et qualifieurs . . . . . . 917

e. Adverbes de négation et d'assertion . . . . . . . . . . . 919

f. Adverbes marquant une relation logique . . . . . . . . . 919

g. L'exemple d'un adverbe modalisateur énonciatif rare et éphémère : quainses . . . . . . . . . . . . . 920 
32.4.1.5 L'évolution des adverbes : modification de leur portée et de leurs valeurs . . . . . . . . . . . . . .

a. Un cas de réorganisation de portée des adverbes quantifieurs intensifieurs : de moult à très et beaucoup $\left(12^{\mathrm{e}}-16^{\mathrm{e}} \mathrm{s}.\right) \ldots \ldots \ldots \ldots \ldots \ldots \ldots \ldots \ldots$

i. Moult intensifieur et quantifieur : portée et position entre le $9^{\mathrm{e}}$ et le $12^{\mathrm{e}} \mathrm{s} \ldots \ldots \ldots \ldots \ldots \ldots 22$

ii. Très et moult $\mathrm{du} 12^{\mathrm{e}}$ au $15^{\mathrm{e}} \mathrm{s}$. . . . . . . . . . . . 925

iii. Beaucoup et moult du $14^{\mathrm{e}}$ au $16^{\mathrm{e}} \mathrm{s} . \ldots \ldots \ldots 926$

iv. Une évolution complexe et une éviction progressive . . . . . . . . . . . . . . . 928

b. De l'adverbe de mot au connecteur : le processus d'élargissement de la portée de l'adverbe : l'exemple de maintenant . . . . . . . . . . . . . . . . . . . . 928

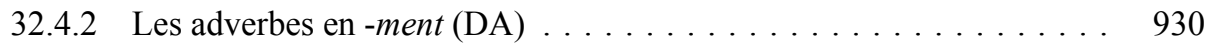

32.4.2.1 Du nom latin mente au suffixe -ment . . . . . . . . . . 930

32.4.2.2 La suffixation en -ment en ancien français et au début du moyen français . . . . . . . . . . . . . . . 932

a. La productivité .................. 932

b. Les variations formelles du radical et du suffixe . . . . 933

i. Les variations du radical . . . . . . . . . . . . . 933

ii. La variation suffixale . . . . . . . . . . . . . . . 934

c. Spécificités catégorielles des bases . . . . . . . . . 934

32.4.2.3 Évolutions ultérieures $\left(15^{\mathrm{e}}-21^{\mathrm{e}} \mathrm{s}.\right) \ldots \ldots \ldots \ldots \ldots \ldots 935$

a. La productivité . . . . . . . . . . . . . . . 935

b. Évolutions formelles du radical . . . . . . . . . . . 935

c. Évolutions catégorielles et sémantiques . . . . . . . 936

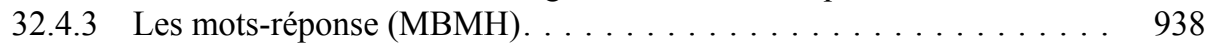

32.4.3.1 Les mots-réponse en français moderne . . . . . . . . . 939

32.4.3.2 L'évolution diachronique des mots-réponse français . . . . . . . . . . . . . . . . . . 941

32.5 Les coordonnants $e t, o u, n i$ et les locutions coordonnantes (CBM) . . . . . . . 944

32.5.1 Du latin au français : « renouvellement des conjonctions » et « tri sélectif » . . . . . . . . . . . . . . . . . . . . . . . . 946

32.5.2 Stabilisation formelle du paradigme français . . . . . . . . . 946

32.5.2.1 Érosion du volume phonétique à l'oral et développement compensatoire des locutions coordonnantes . . . . . . . . 946

a. Érosion du volume phonétique . . . . . . . . . . . 946

b. Développement compensatoire de locutions coordonnantes : ou bien, ou soit, et si, ne mais (que) . . . . . . . . . . . . . . . . 949

i. Ou est susceptible d'entrer en composition avec bien et avec soit . . . . . . . . . . . . . . 950

ii. Et a pu pour sa part entrer pour un temps en composition avec $s i . \ldots \ldots \ldots \ldots \ldots \ldots . \ldots 53$

iii. $\mathrm{Ne} / n i$, à la différence de $O u$ et $E t$, n'est à l'origine d'aucune locution coordonnante . . . . . . . . . 954 
L Table des matières

32.5.2.2 «Effort de distinction graphique » à l'écrit et macrogrammaticalisations .................. 954

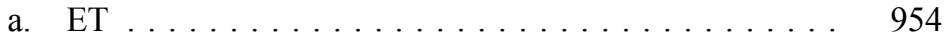

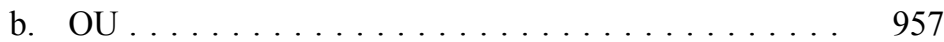

c. $\mathrm{NE}$ et $\mathrm{NI} \ldots \ldots \ldots \ldots \ldots \ldots \ldots \ldots$ 